\title{
Discovery of Novel and Highly Potent Resorcinol Dibenzyl Ether-based PD-1/PD-L1 Inhibitors with Improved Drug-like and Pharmacokinetic Properties for Cancer Treatment
}

Binbin Cheng ${ }^{1}$, Wei Wang ${ }^{1}$, Xiaoge Niu ${ }^{1}$, Yichang Ren ${ }^{1}$, Ting Liu ${ }^{1}$, Hao Cao ${ }^{1}$, Shuanghu Wang ${ }^{1}$, Yingfeng Tu ${ }^{1}$,Jingxuan Chen ${ }^{1}$, Shuwen Liu ${ }^{1}$, Xuchao Yang ${ }^{1}$, Jianjun Chen ${ }^{1 *}$

${ }^{1}$ School of Pharmaceutical Sciences, Guangdong Provincial Key Laboratory of New Drug Screening, Southern Medical University, Guangzhou 510515, China.

*Corresponding Author: Jianjun Chen. School of Pharmaceutical Sciences, Guangdong Provincial Key Laboratory of New Drug Screening, Southern Medical University, Guangzhou 510515, China. Email: jchen21@smu.edu.cn.

KEYWORDS: water-soluble; immunotherapy; small molecule PD-1/PD-L1 inhibitors.

Table of Contents

Copies of PD-1/PD-L1 small molecules ${ }^{1} \mathrm{H}$ NMR, ${ }^{13} \mathrm{C}$ NMR, HRMS, and HPLC spectra. S2 


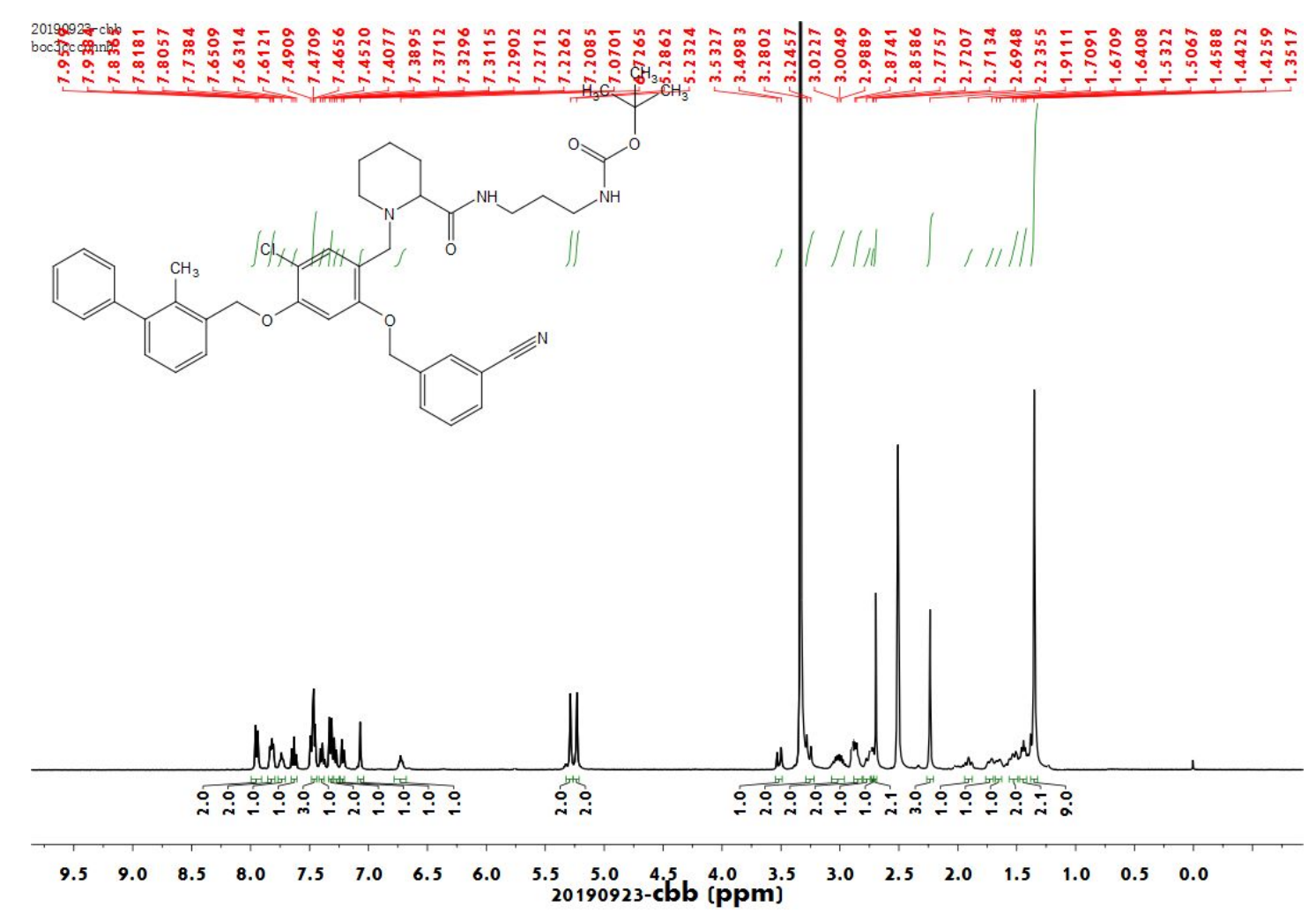

${ }^{1} \mathrm{H}$ NMR of compound $\mathbf{P 1}$.

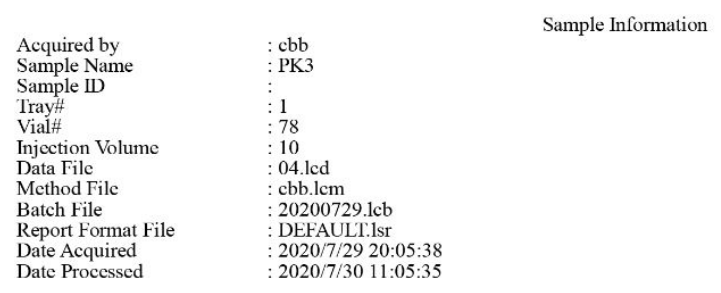

$\mathrm{mV}$

Chromatogram
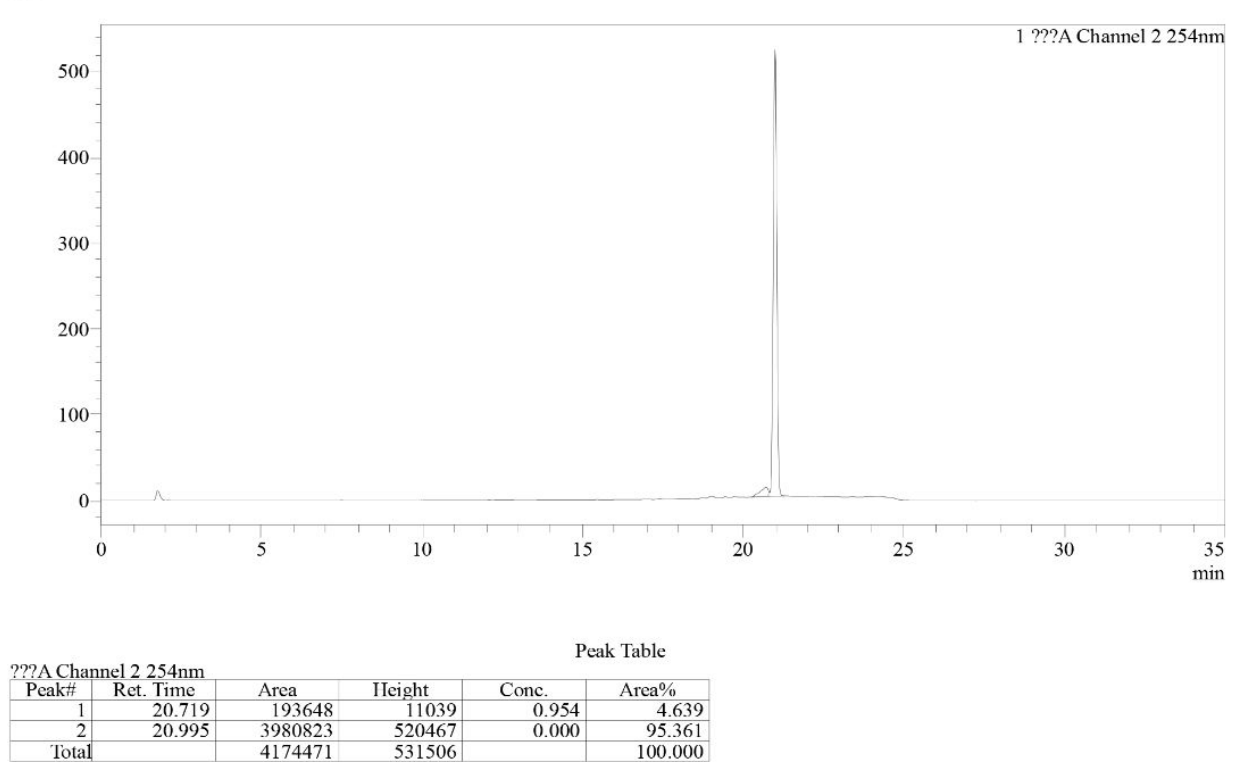

HPLC of compound P1. 


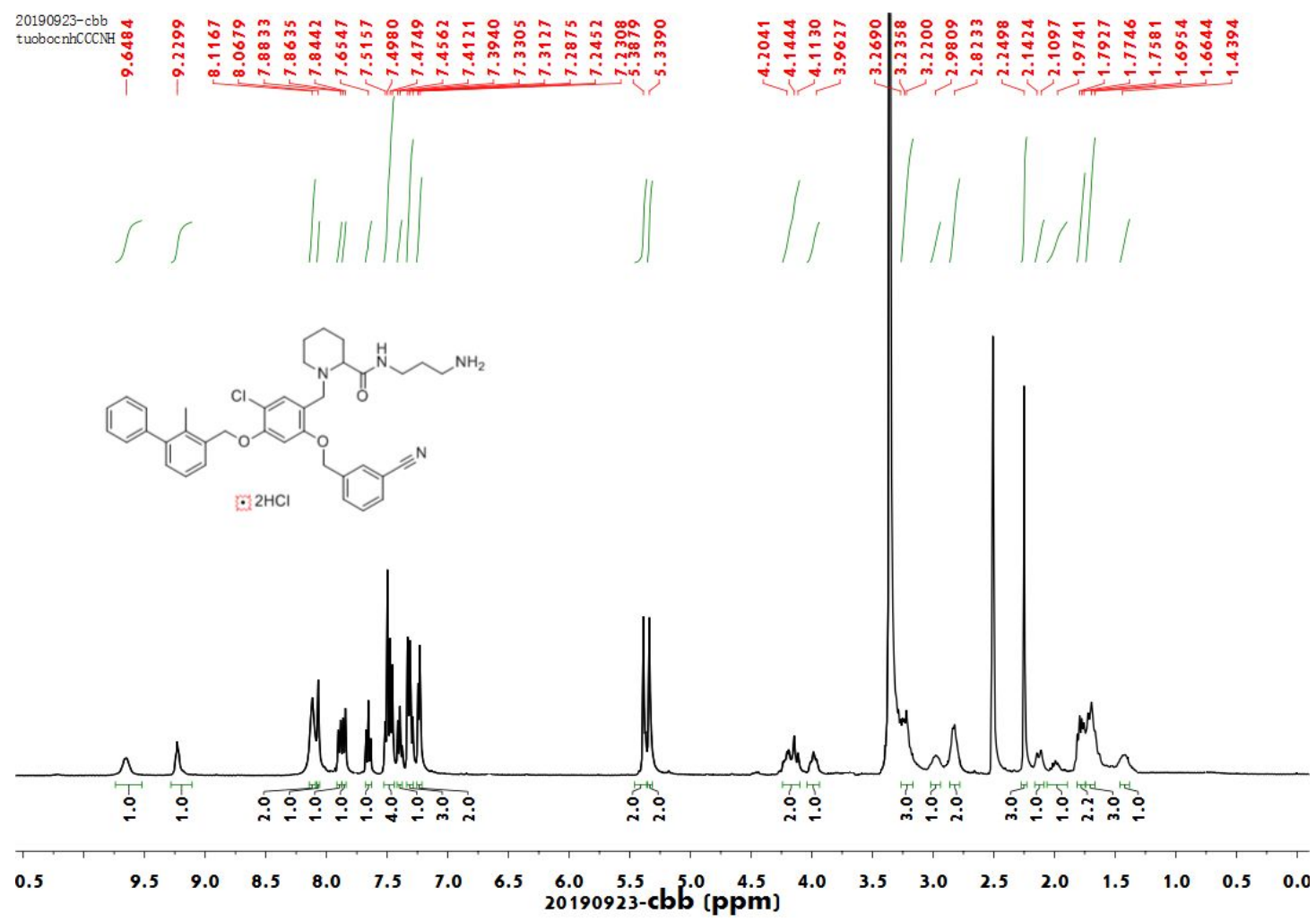

${ }^{1} \mathrm{H}$ NMR of compound P2.

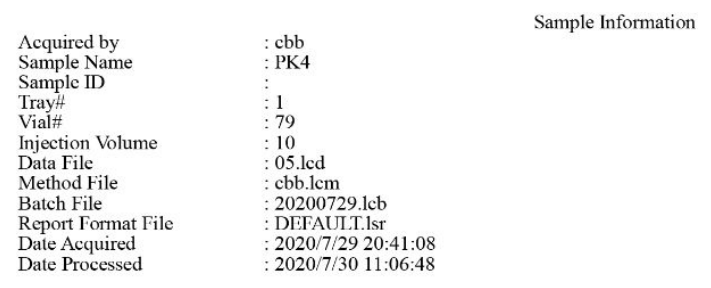

$\mathrm{mV}$

Chromatogram
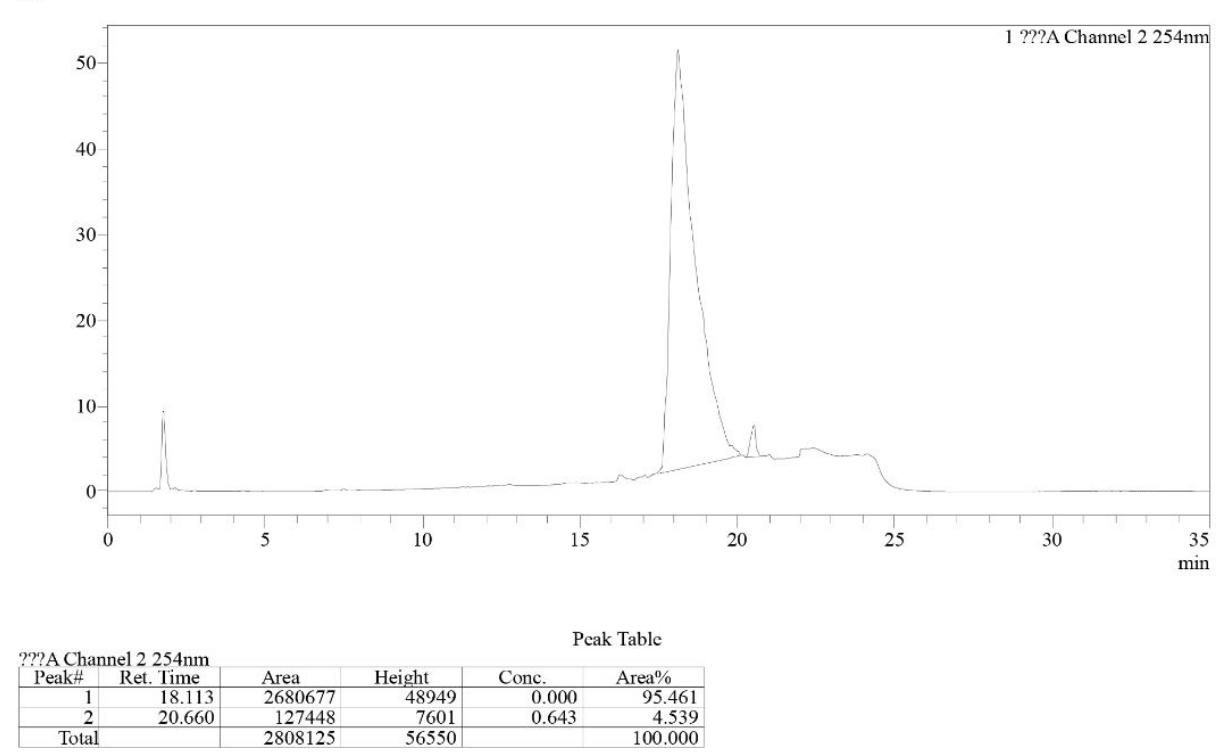

HPLC of compound P2. 


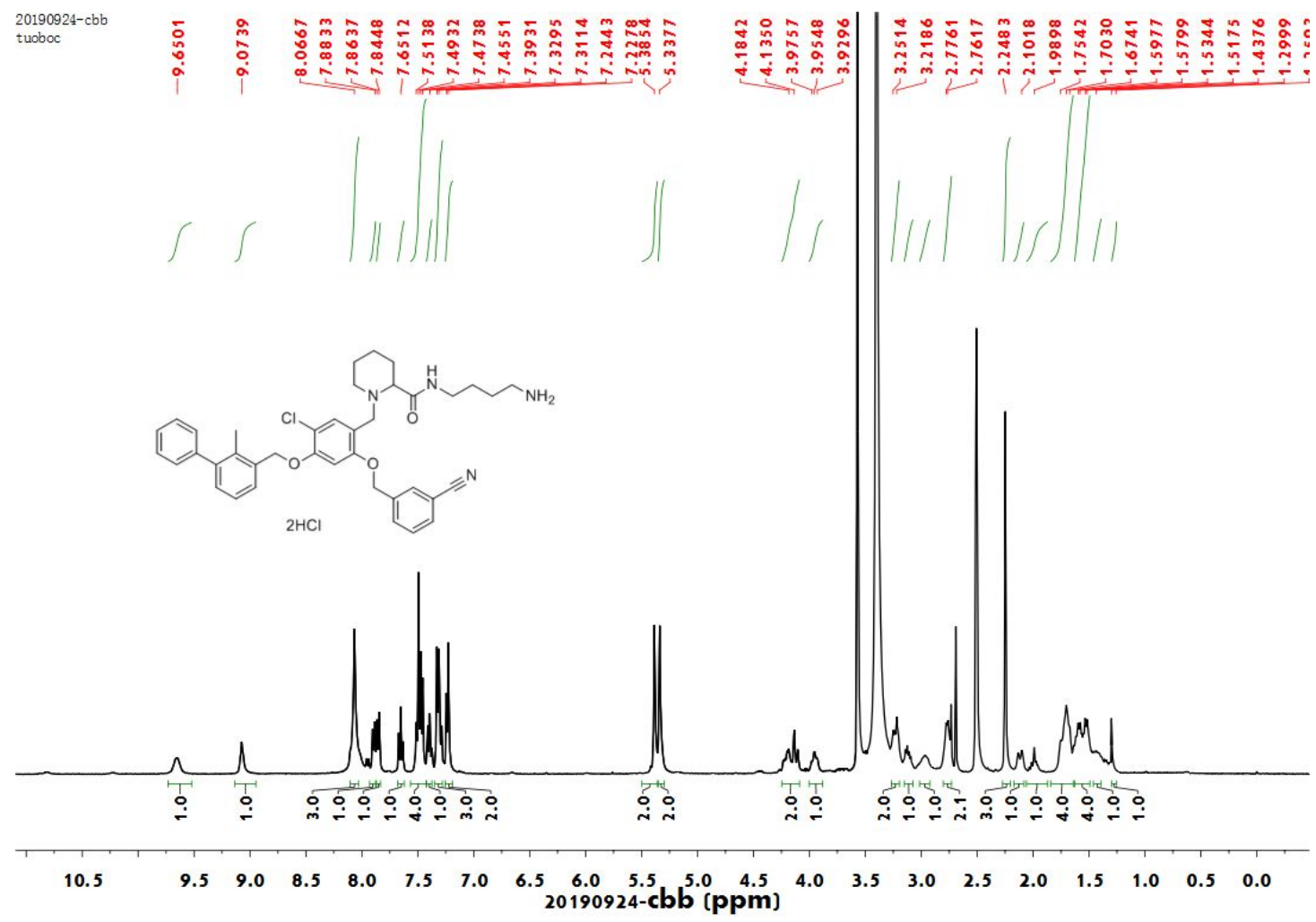

${ }^{1} \mathrm{H}$ NMR of compound P3.

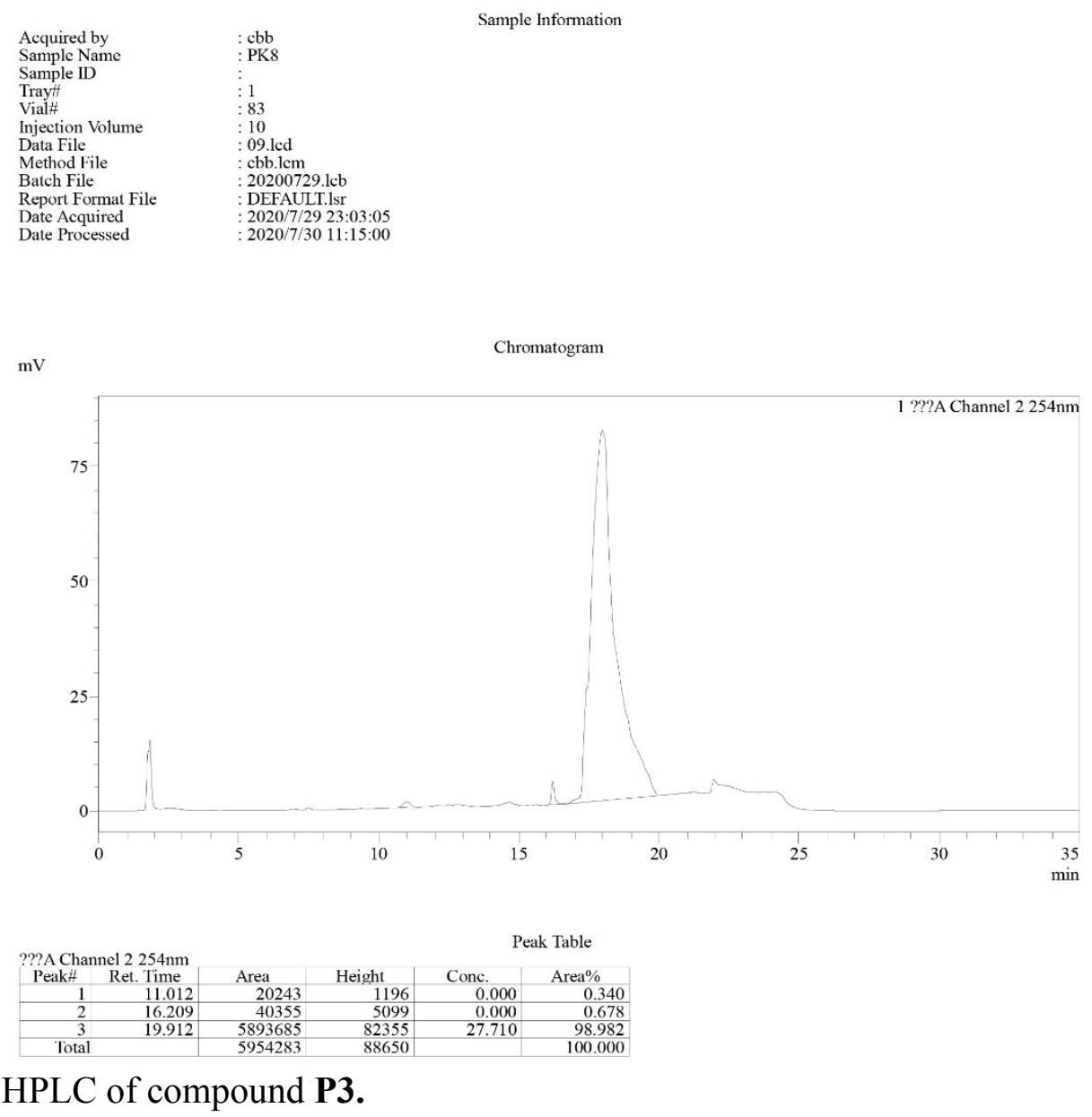




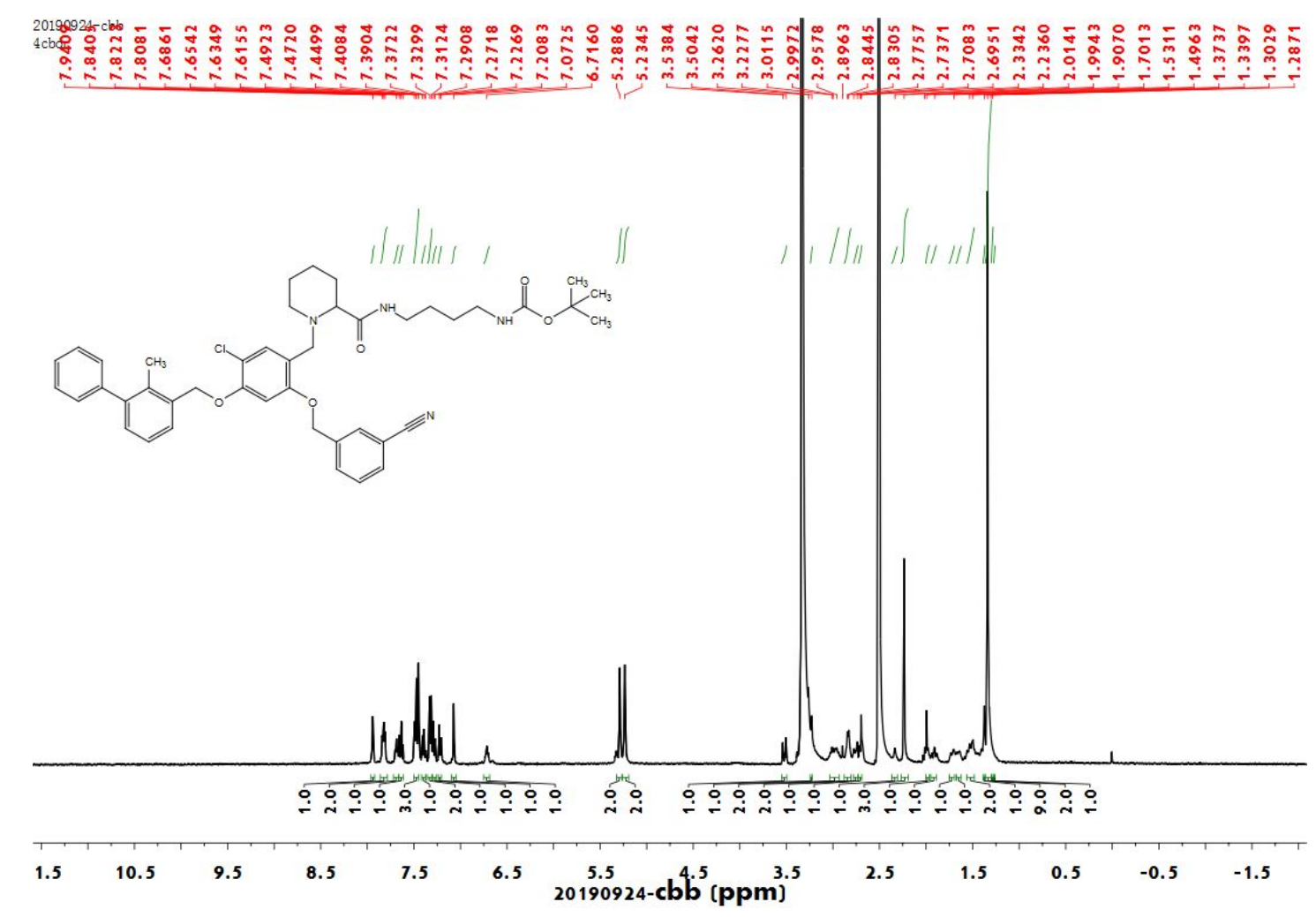

${ }^{1} \mathrm{H}$ NMR of compound $\mathbf{P 4}$.

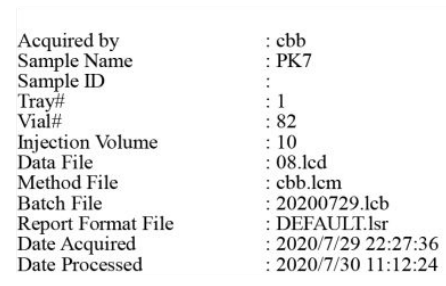

Sample Information

$\mathrm{mV}$

Chromatogram

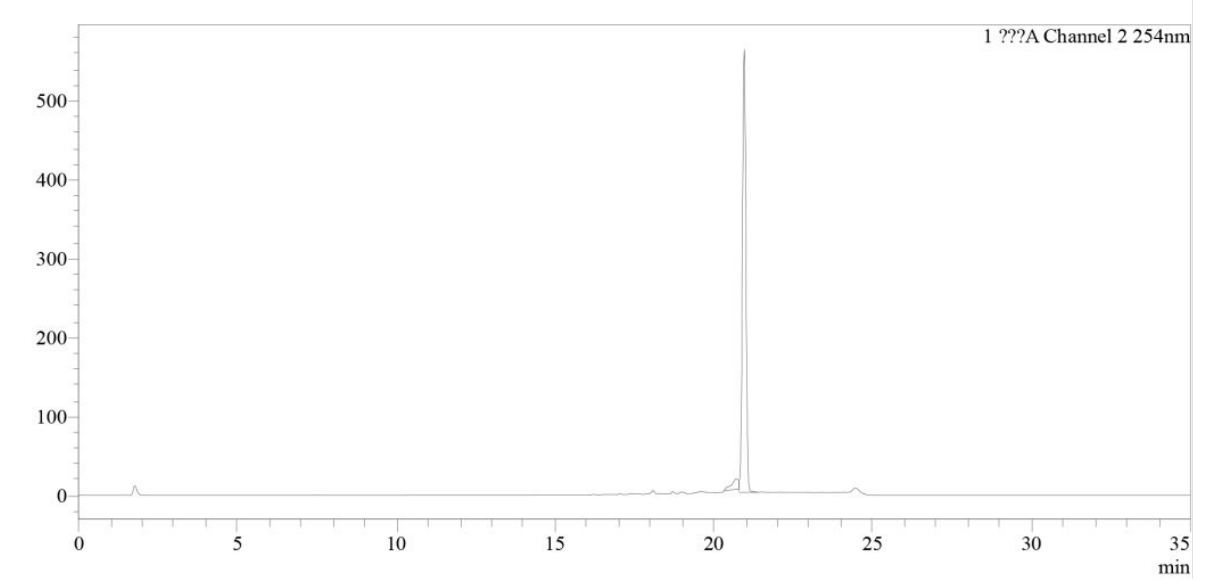

Peak Table

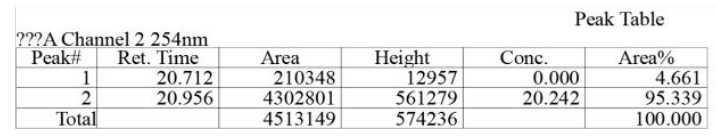

HPLC of compound $\mathbf{P 4}$. 


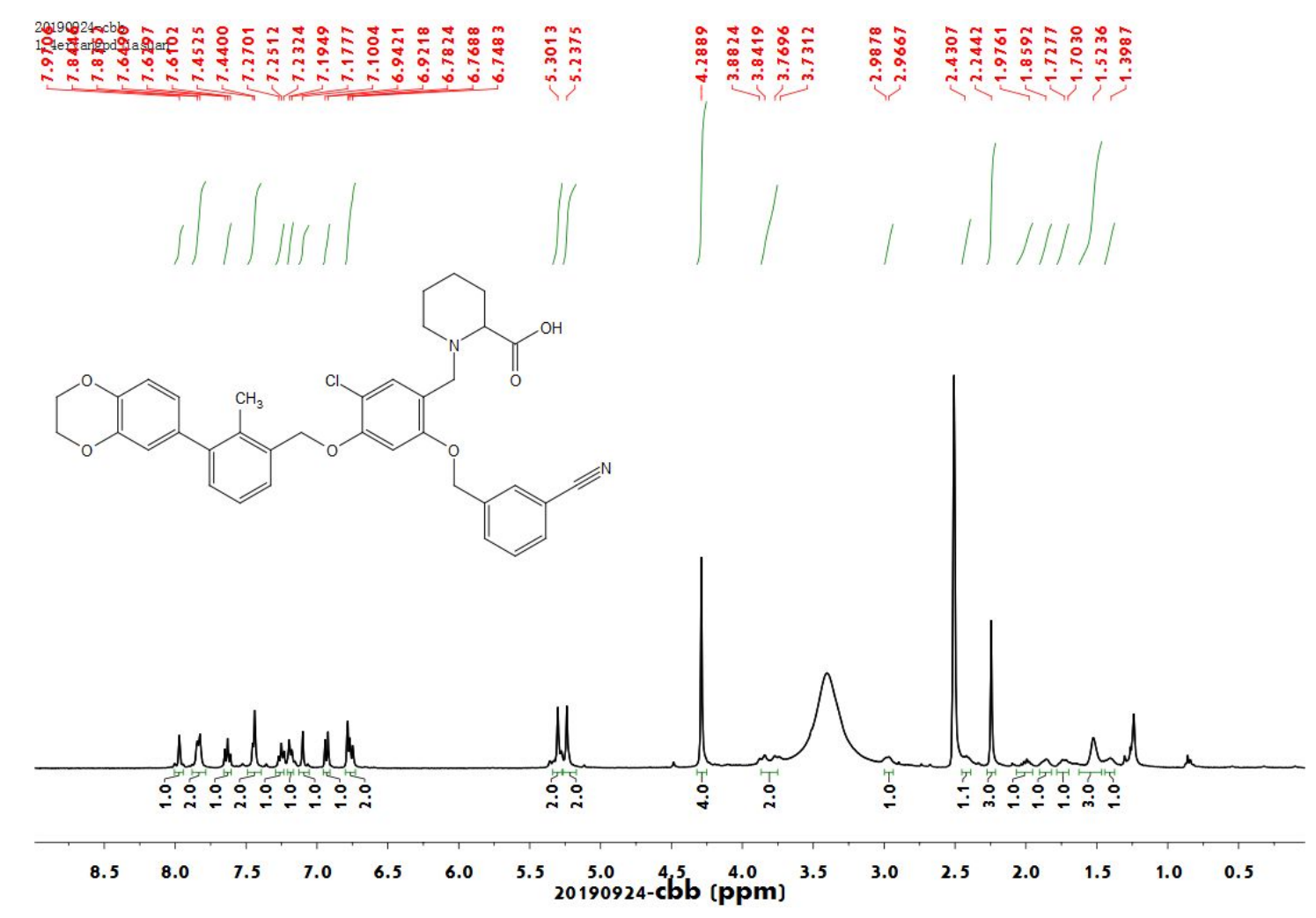

${ }^{1} \mathrm{H}$ NMR of compound P5.

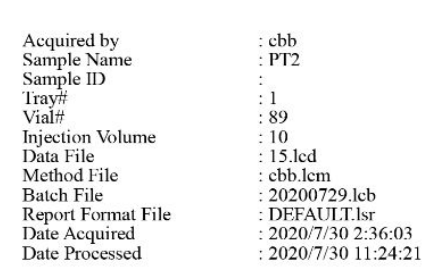

Sample Information

$\mathrm{mV}$

Chromatogram

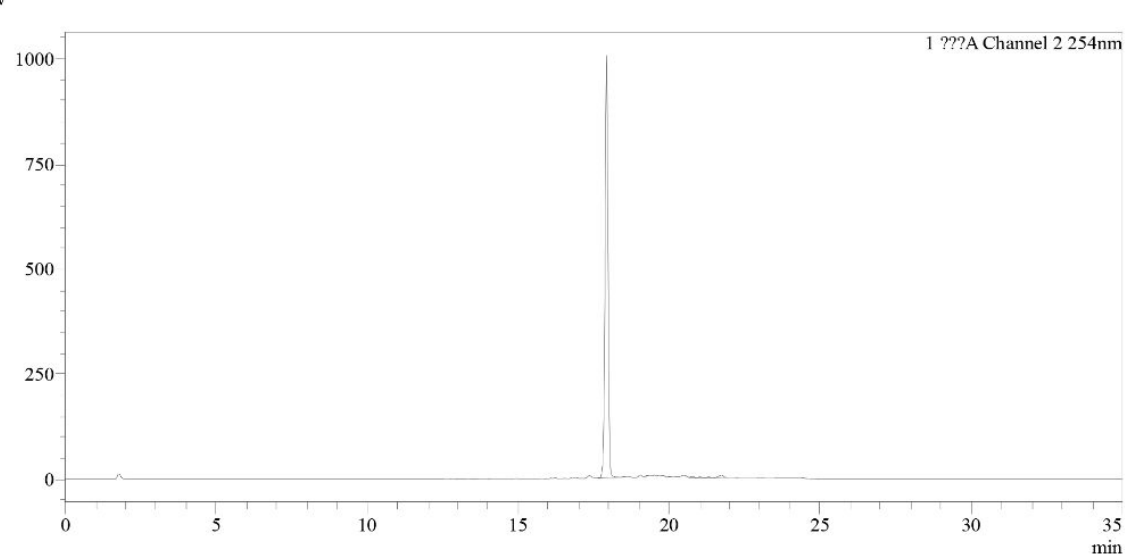

Peak Table

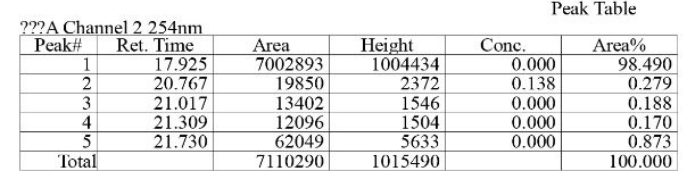

HPLC of compound P5. 


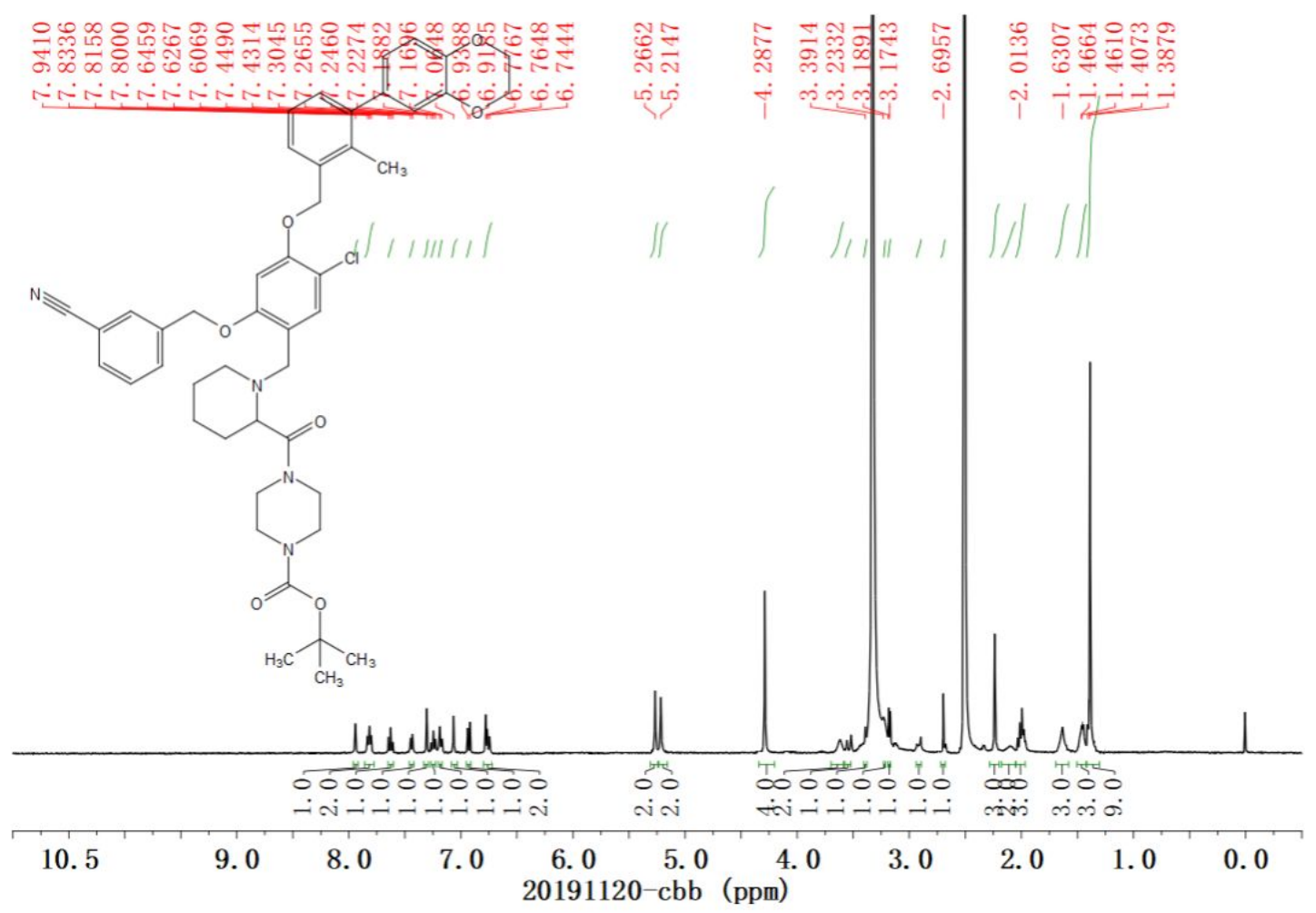

${ }^{1} \mathrm{H}$ NMR of compound $\mathbf{P 6}$.

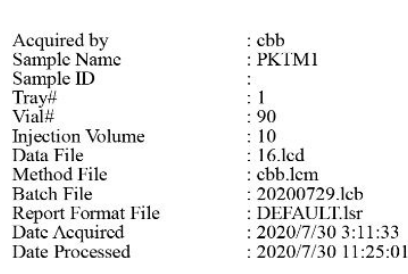

Sample Information

$\mathrm{mV}$

Chromatogram

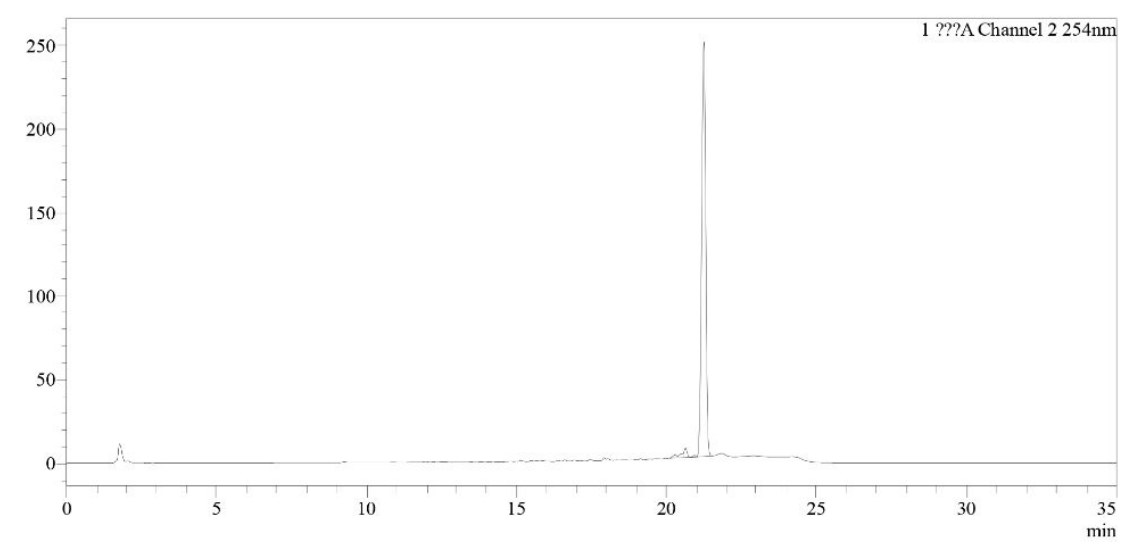

Peak Table

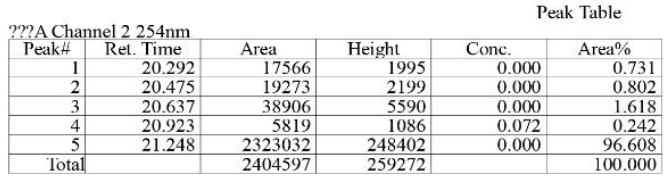

HPLC of compound P6. 


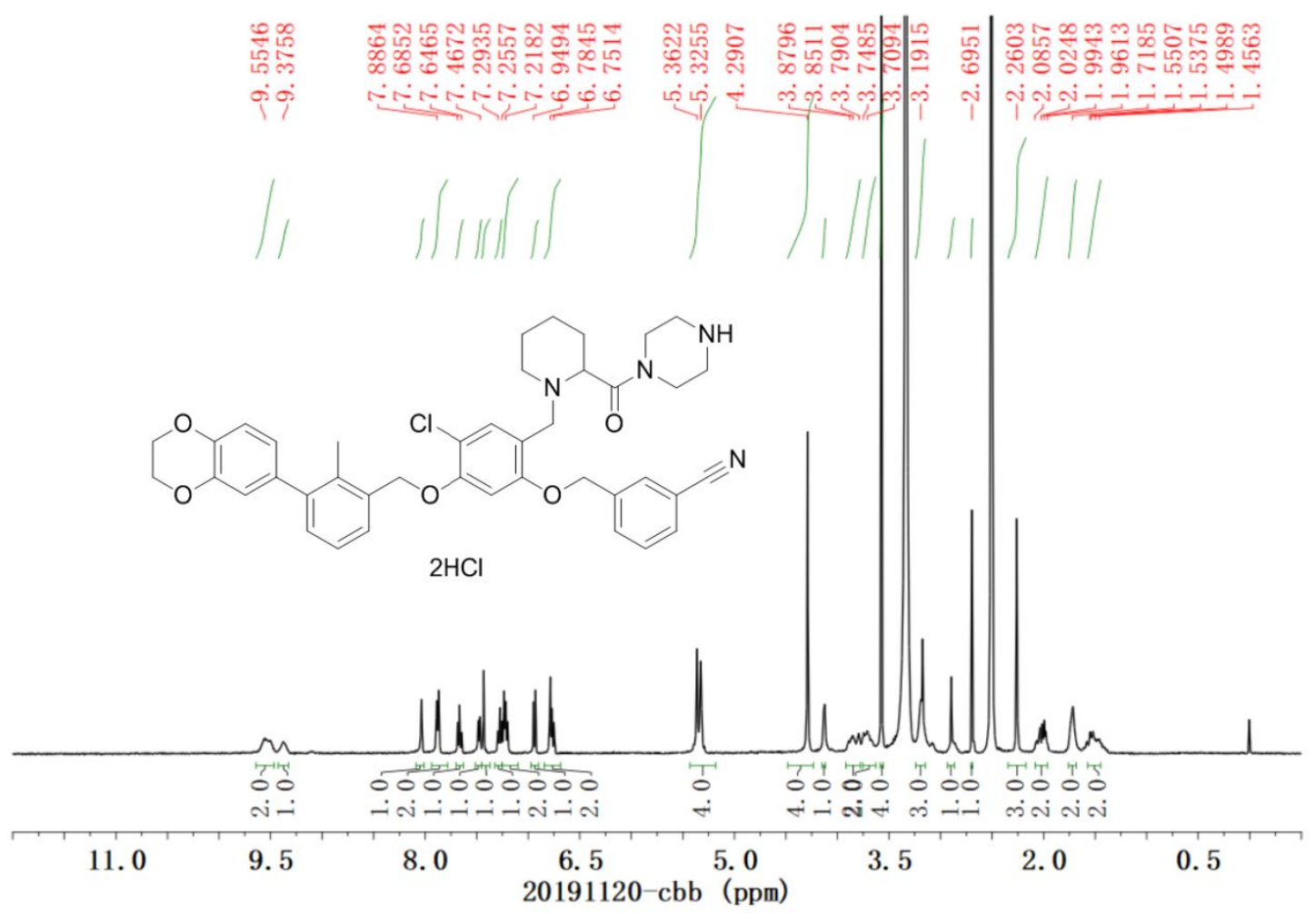

${ }^{1} \mathrm{H}$ NMR of compound P7.

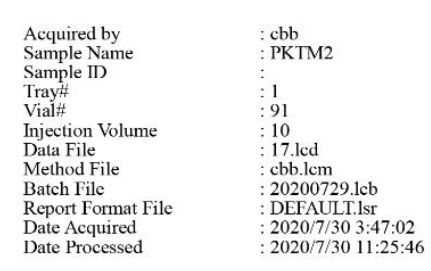

Sample Information

$\mathrm{mV}$

Chromatogram

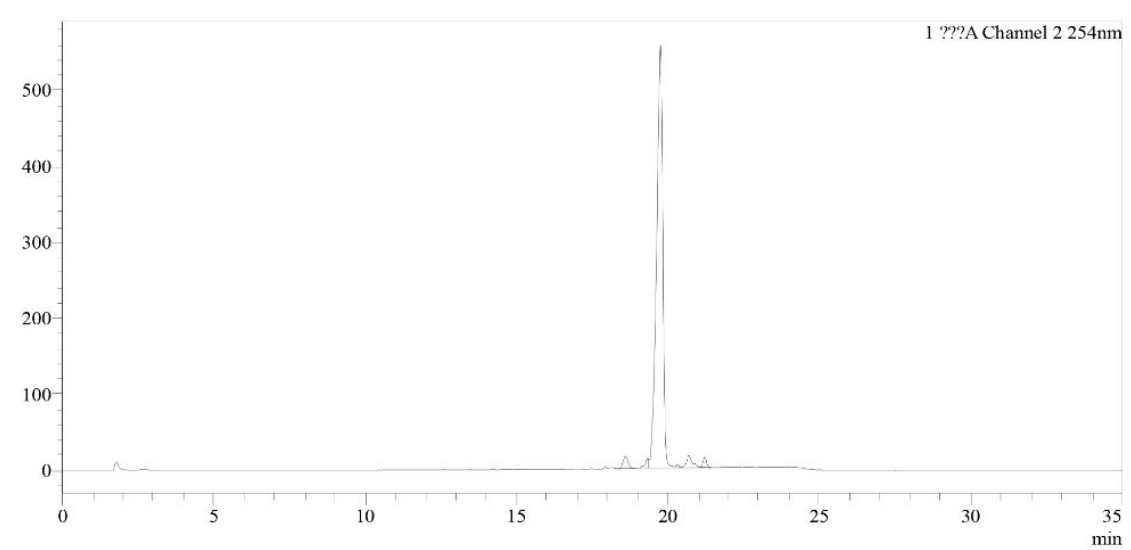

Peak Table

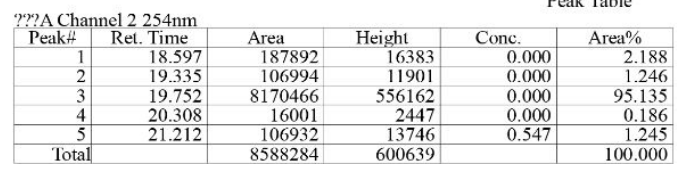

HPLC of compound P7. 


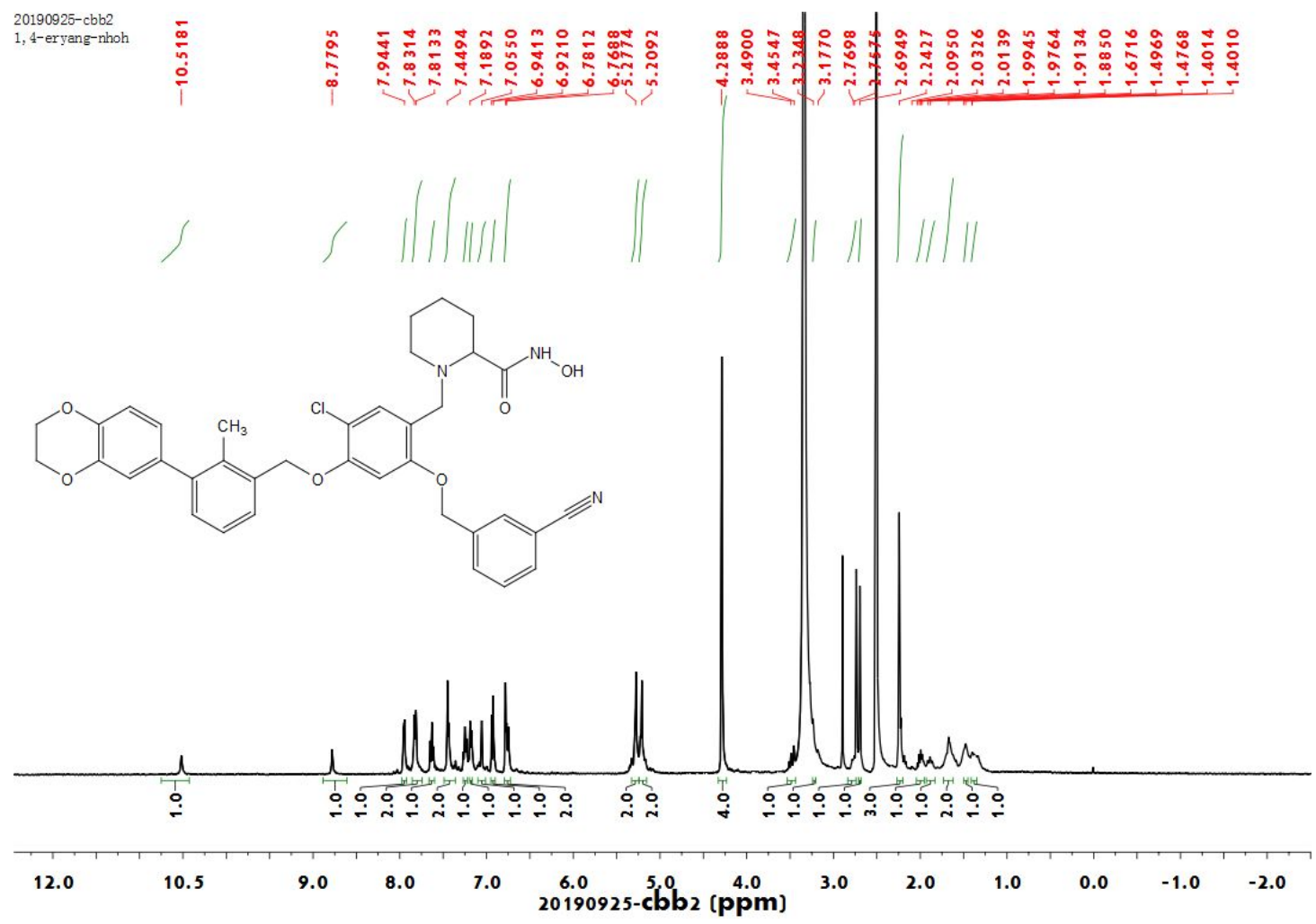

${ }^{1} \mathrm{H}$ NMR of compound $\mathbf{P 8 .}$

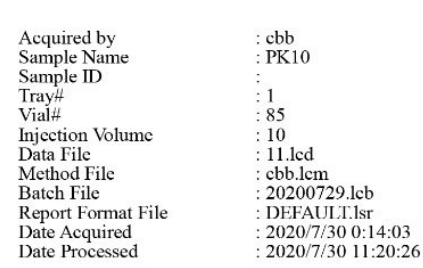

Sample Information
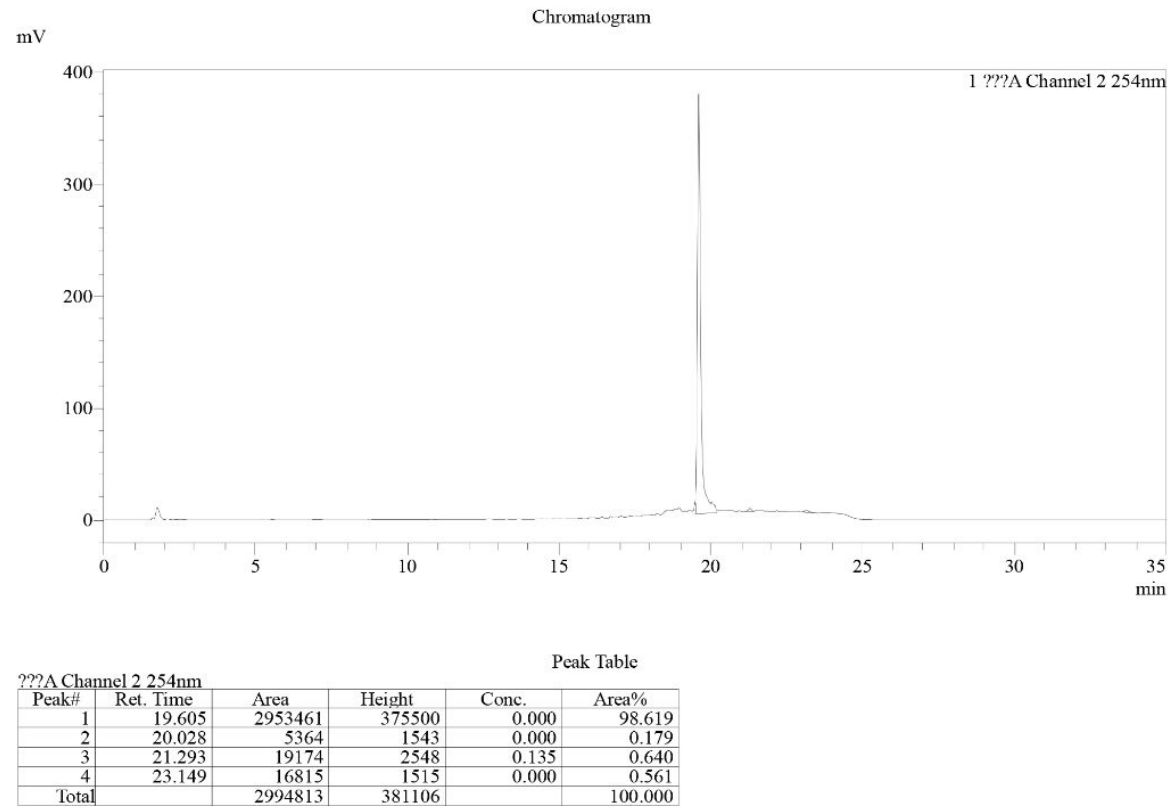

HPLC of compound P8. 

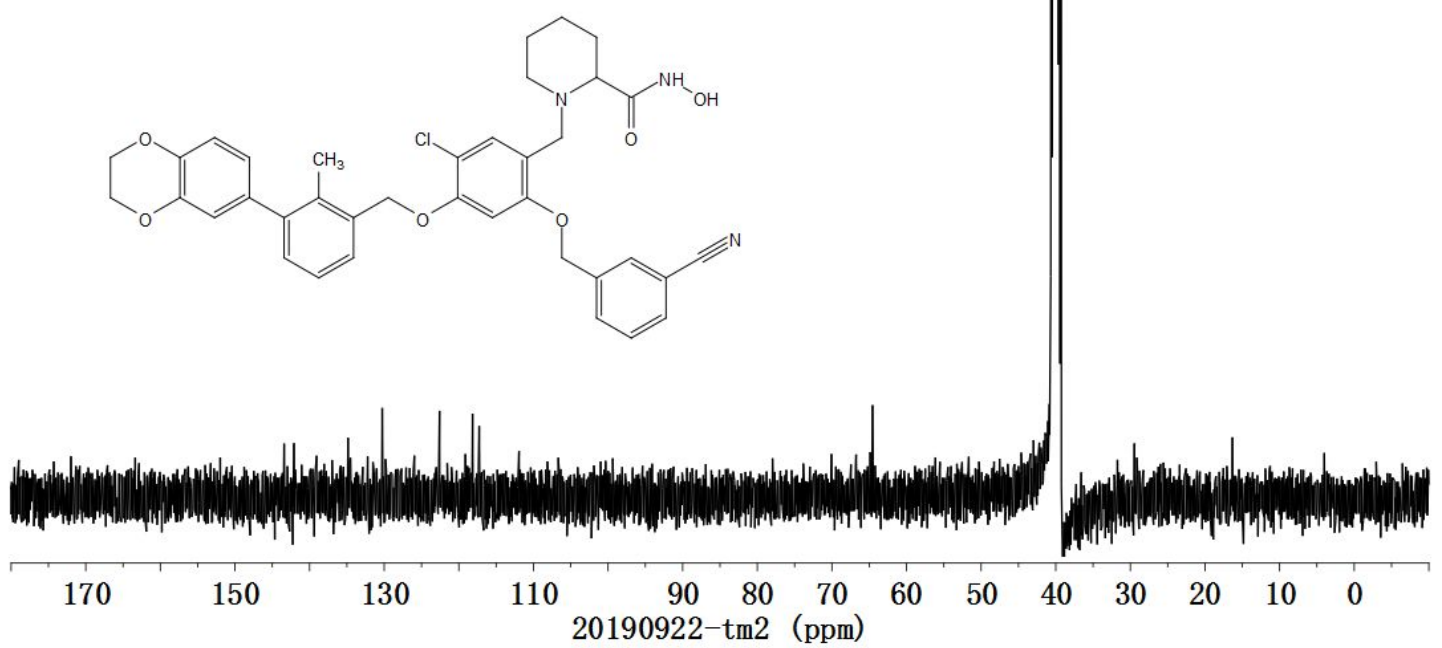

${ }^{13} \mathrm{C}$ NMR of compound P8.

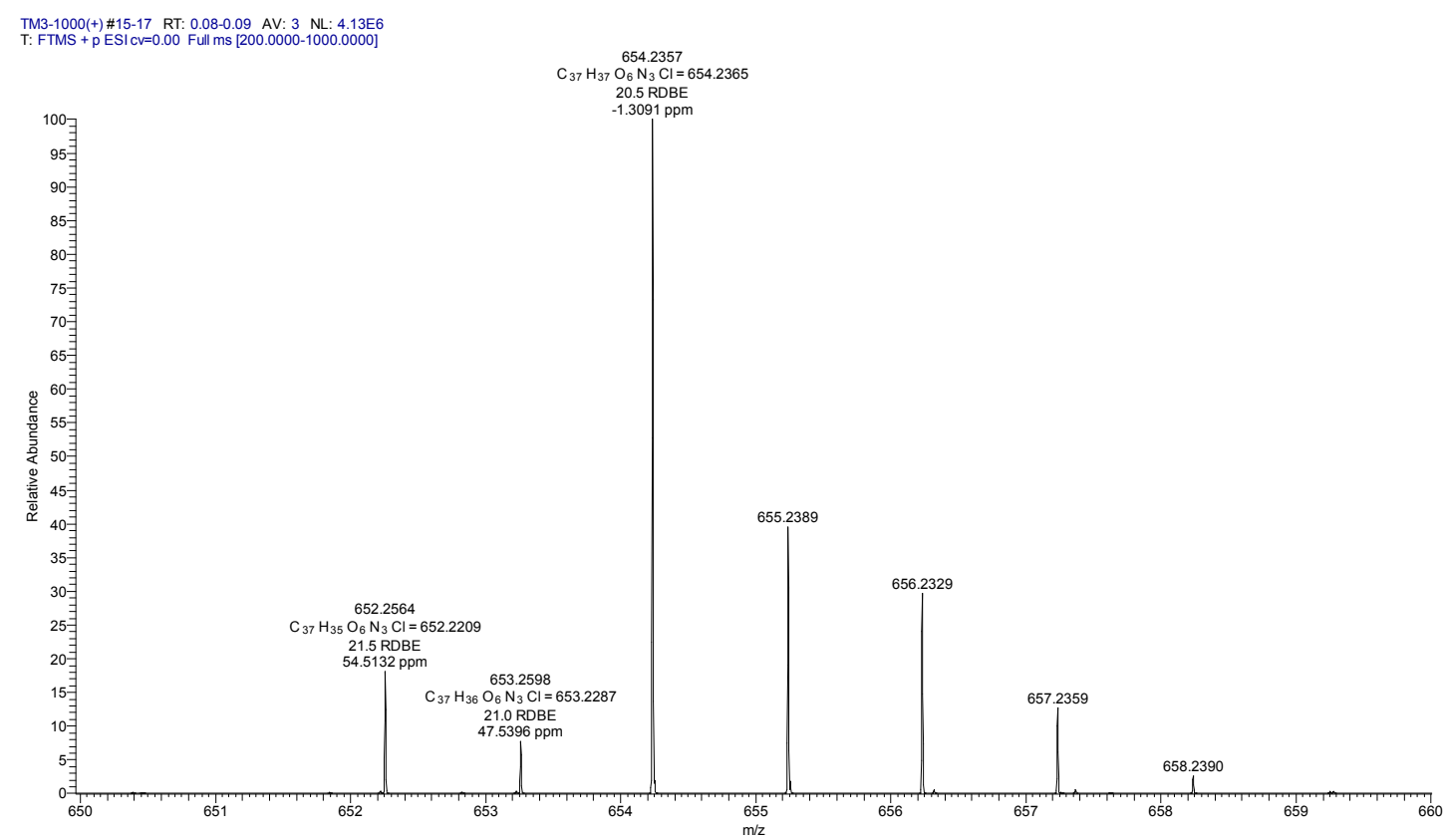

HRMS of compound P8. 


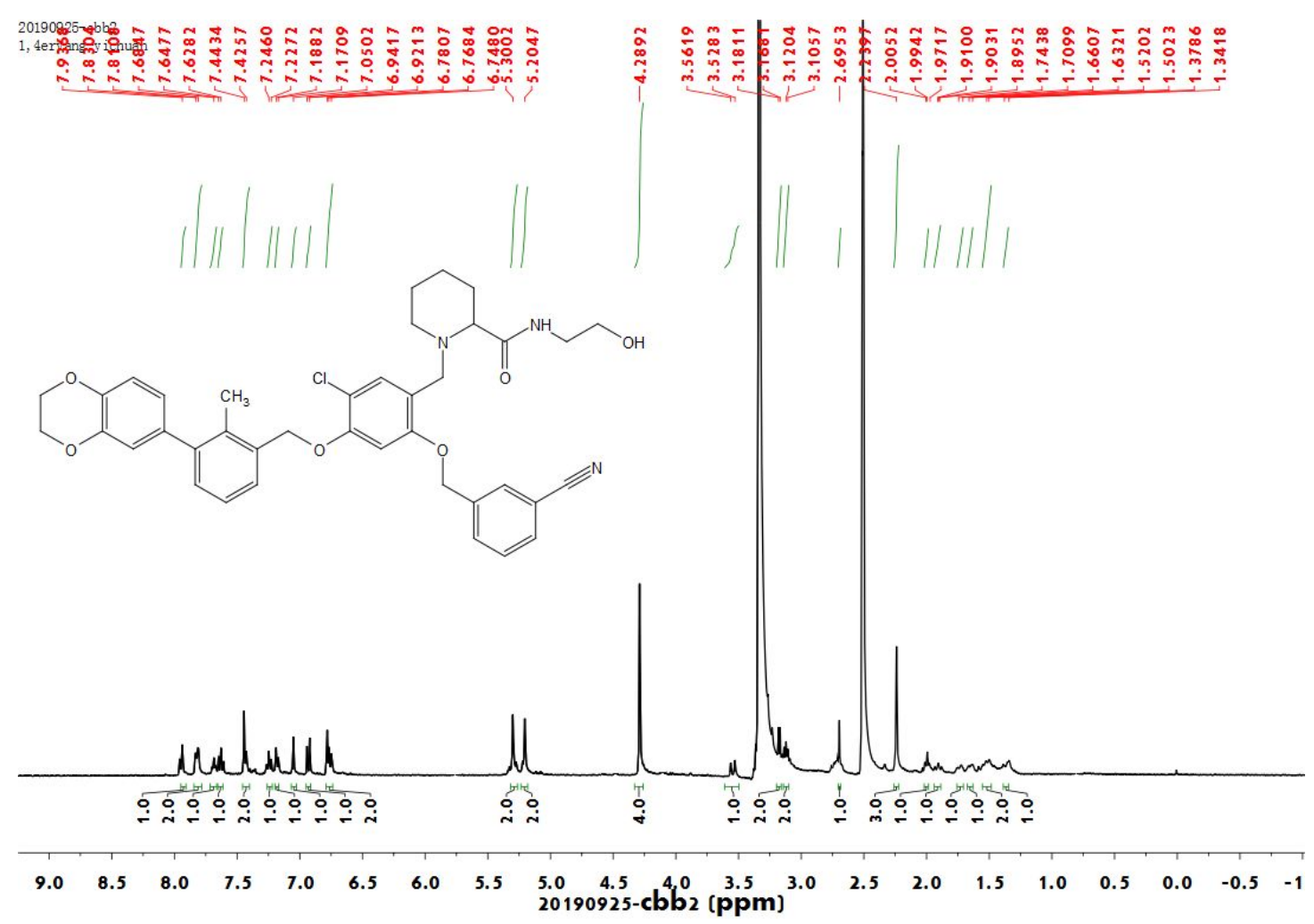

${ }^{1} \mathrm{H}$ NMR of compound P9.

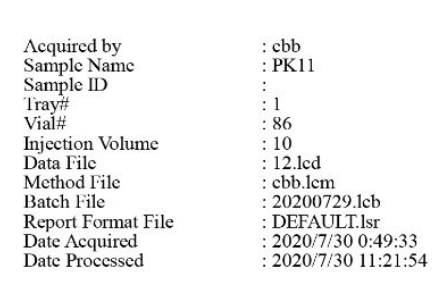

Sample Information

mV

Chromatogram
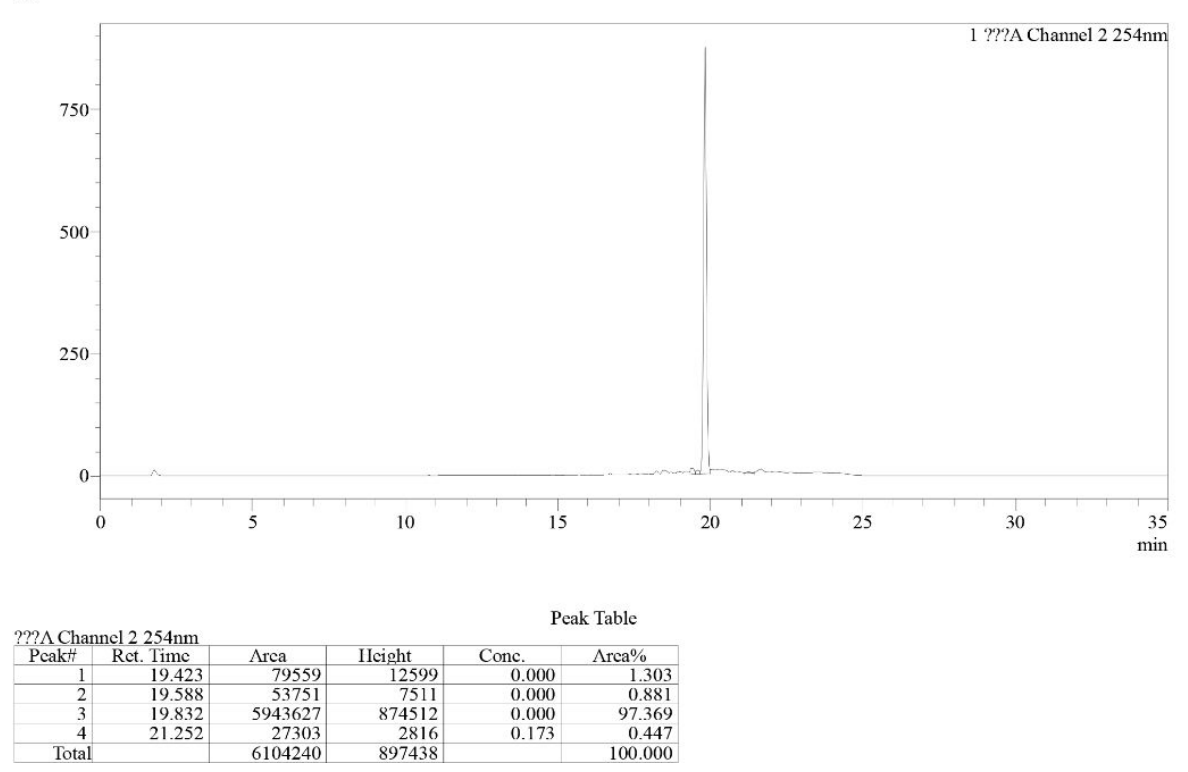

HPLC of compound P9. 


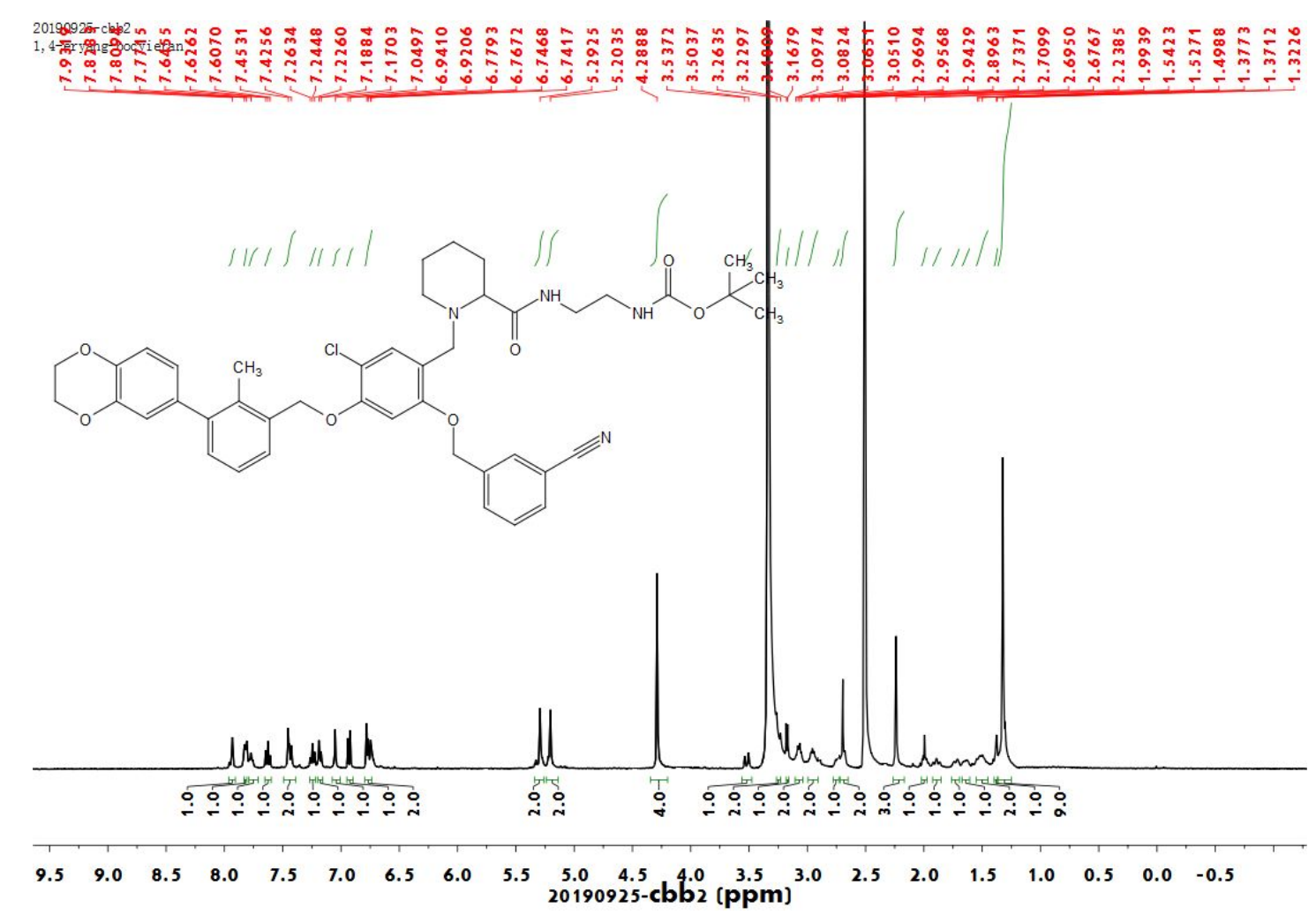

${ }^{1} \mathrm{H}$ NMR of compound P10.

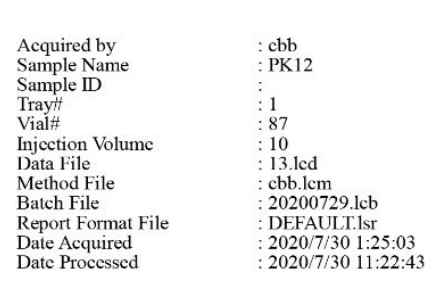

Sample Information
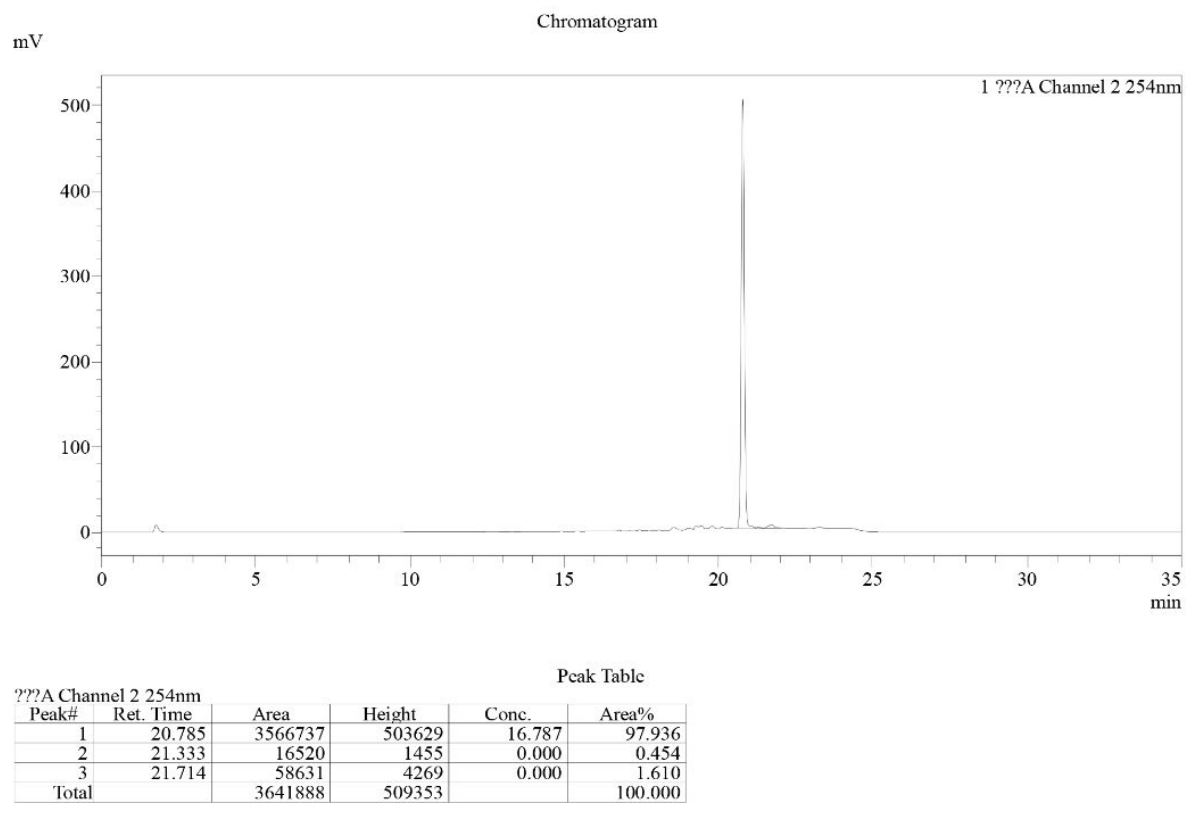

HPLC of compound P10. 


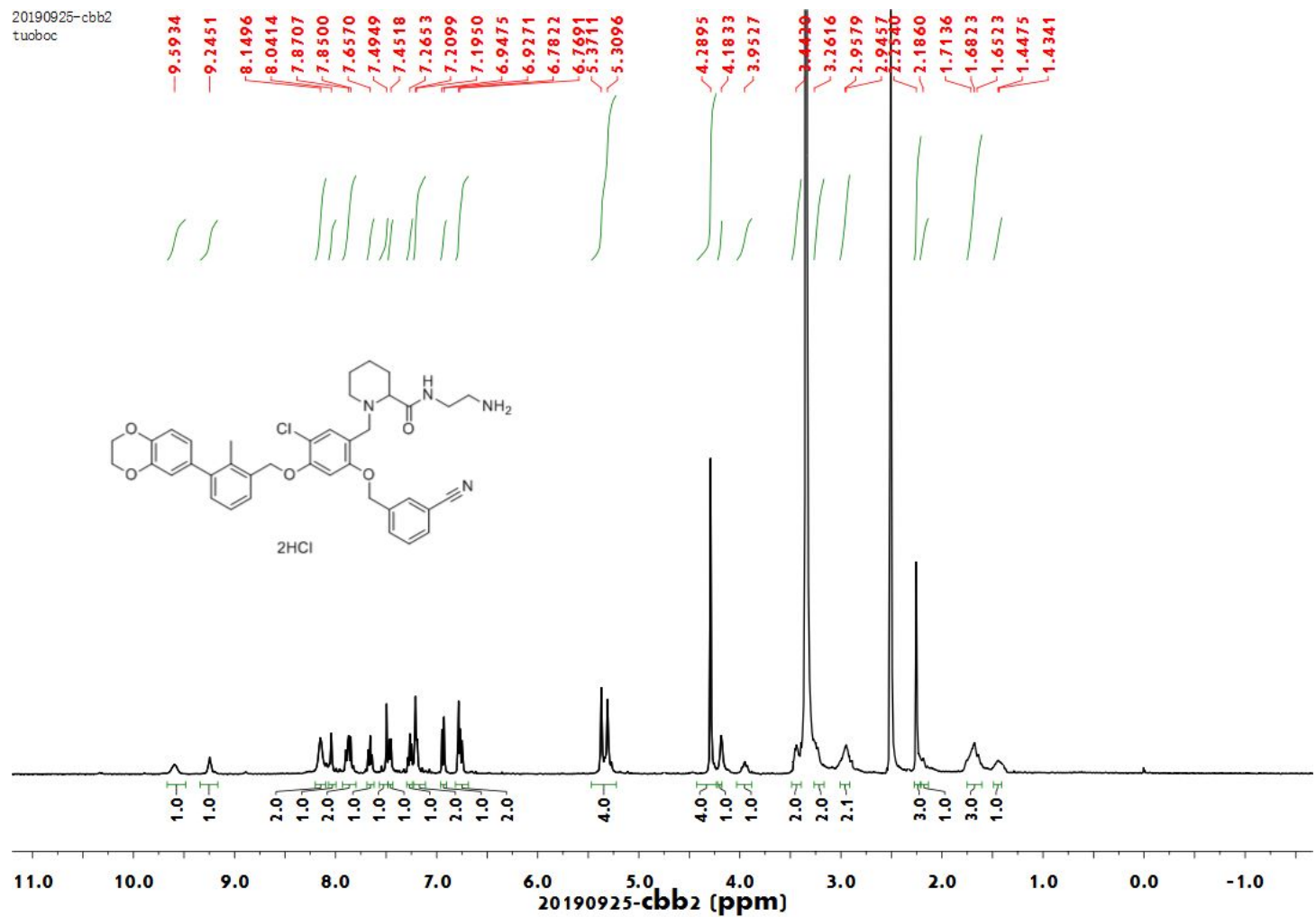

${ }^{1} \mathrm{H}$ NMR of compound P11.
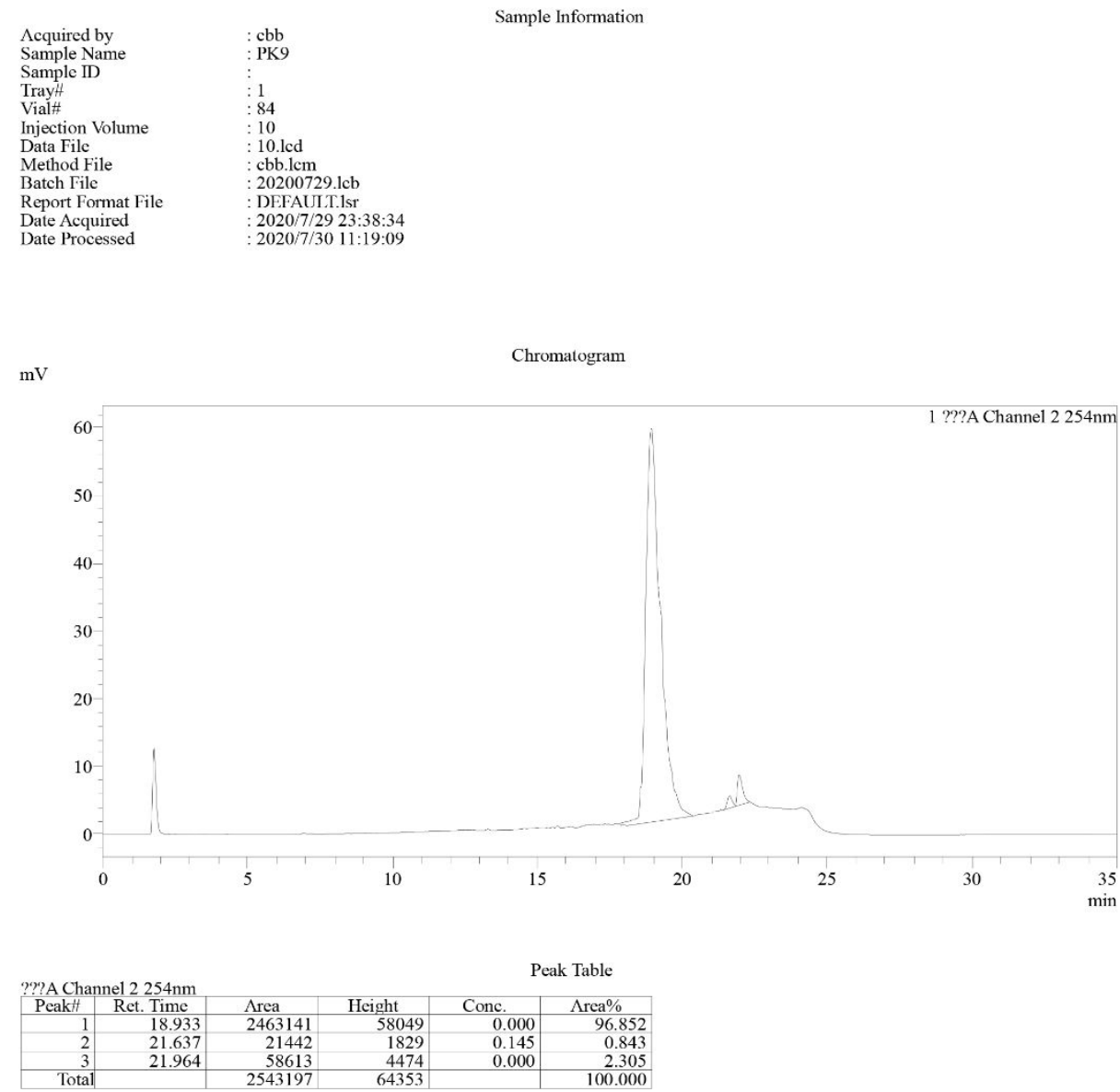

HPLC of compound P11. 


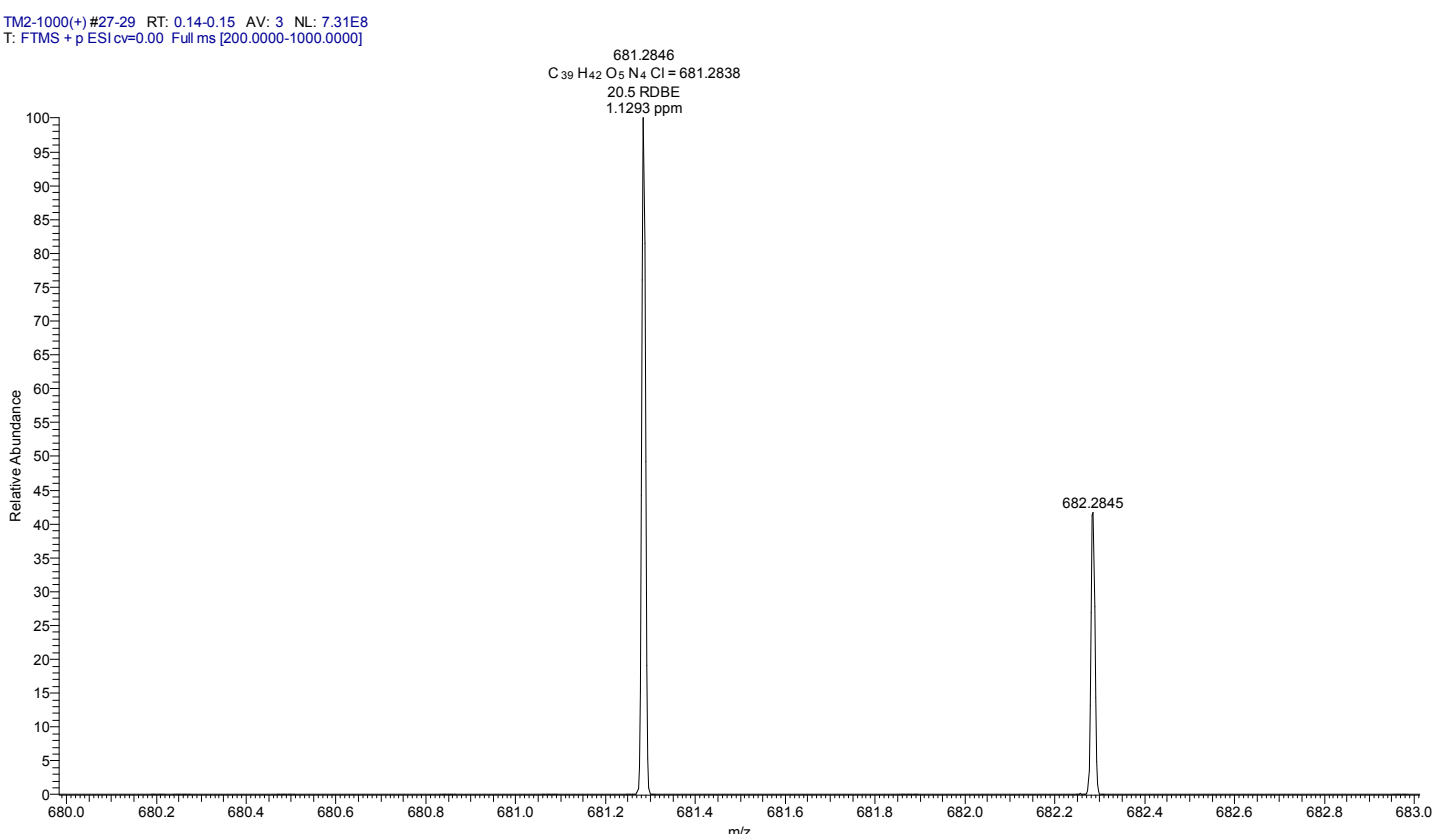

HRMS of compound P11.

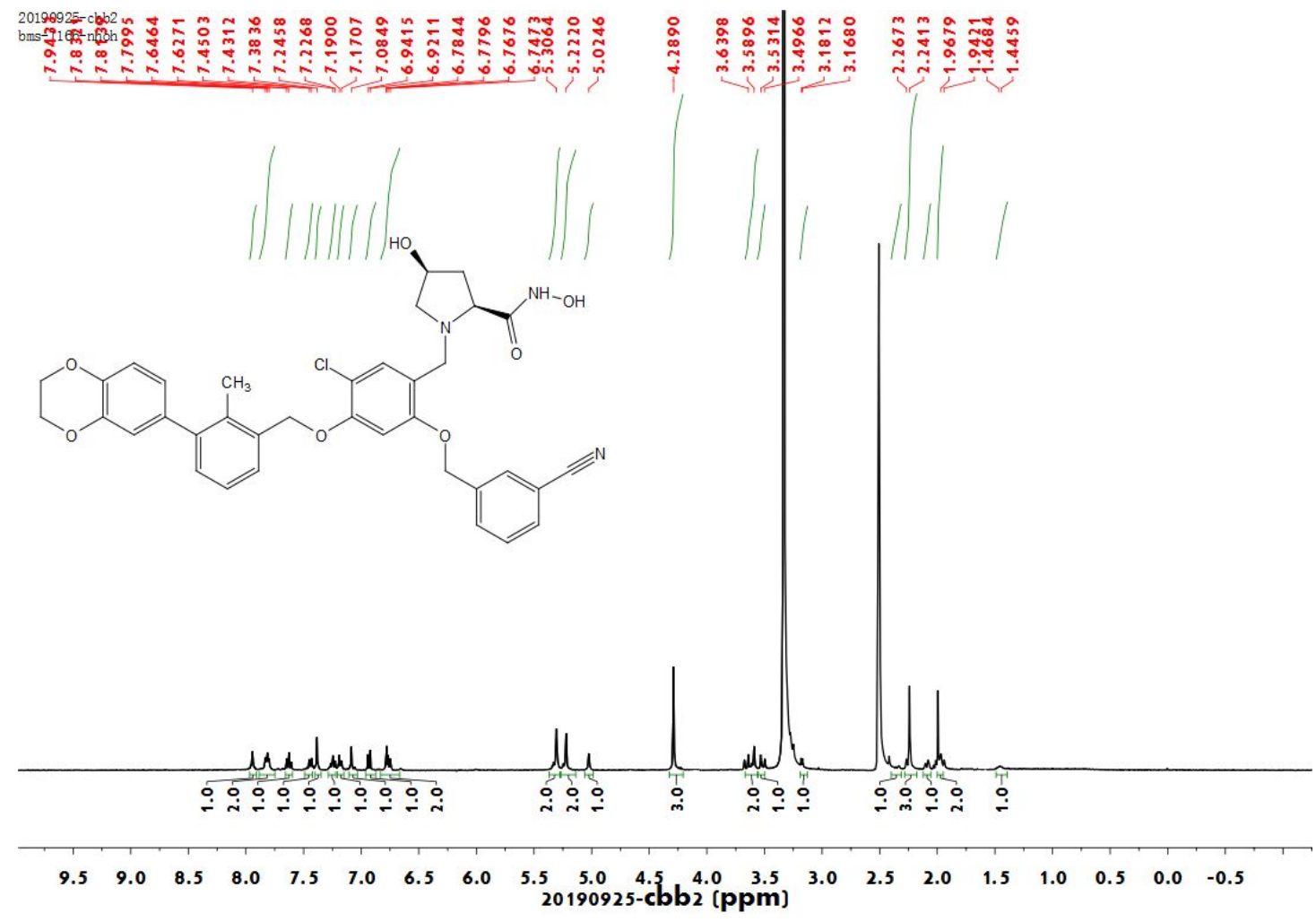

${ }^{1} \mathrm{H}$ NMR of compound P12. 


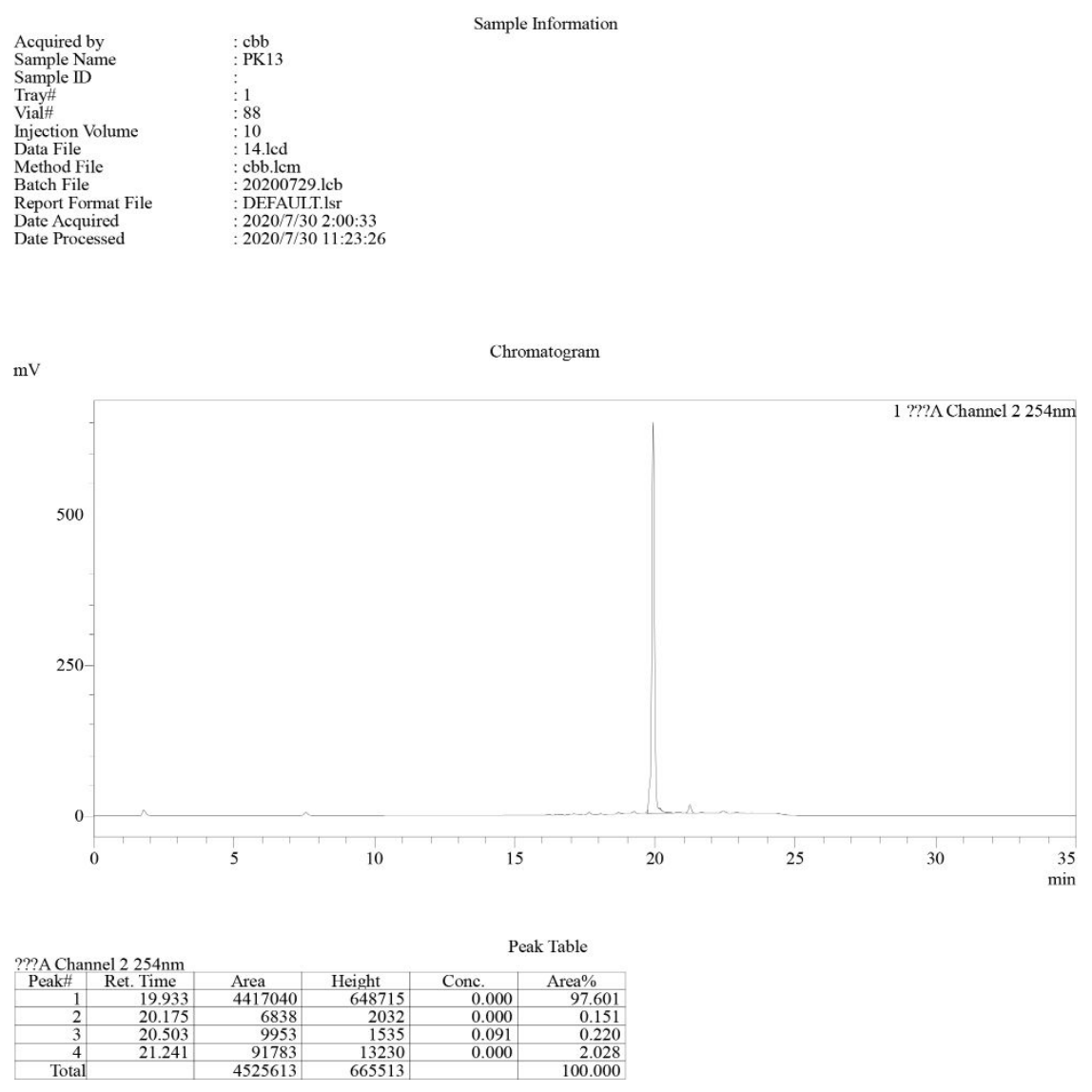

HPLC of compound P12.

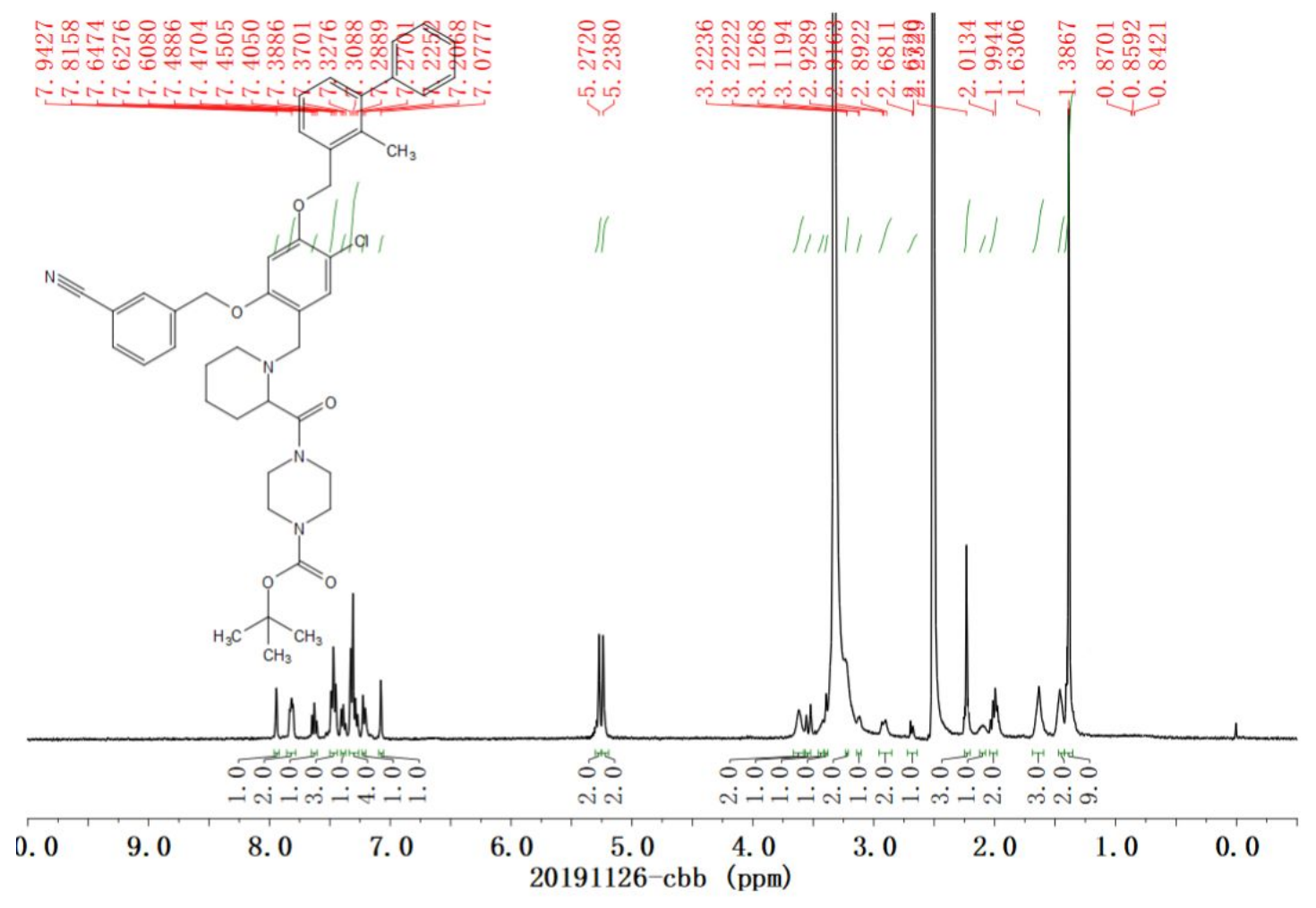

${ }^{1} \mathrm{H}$ NMR of compound P13. 

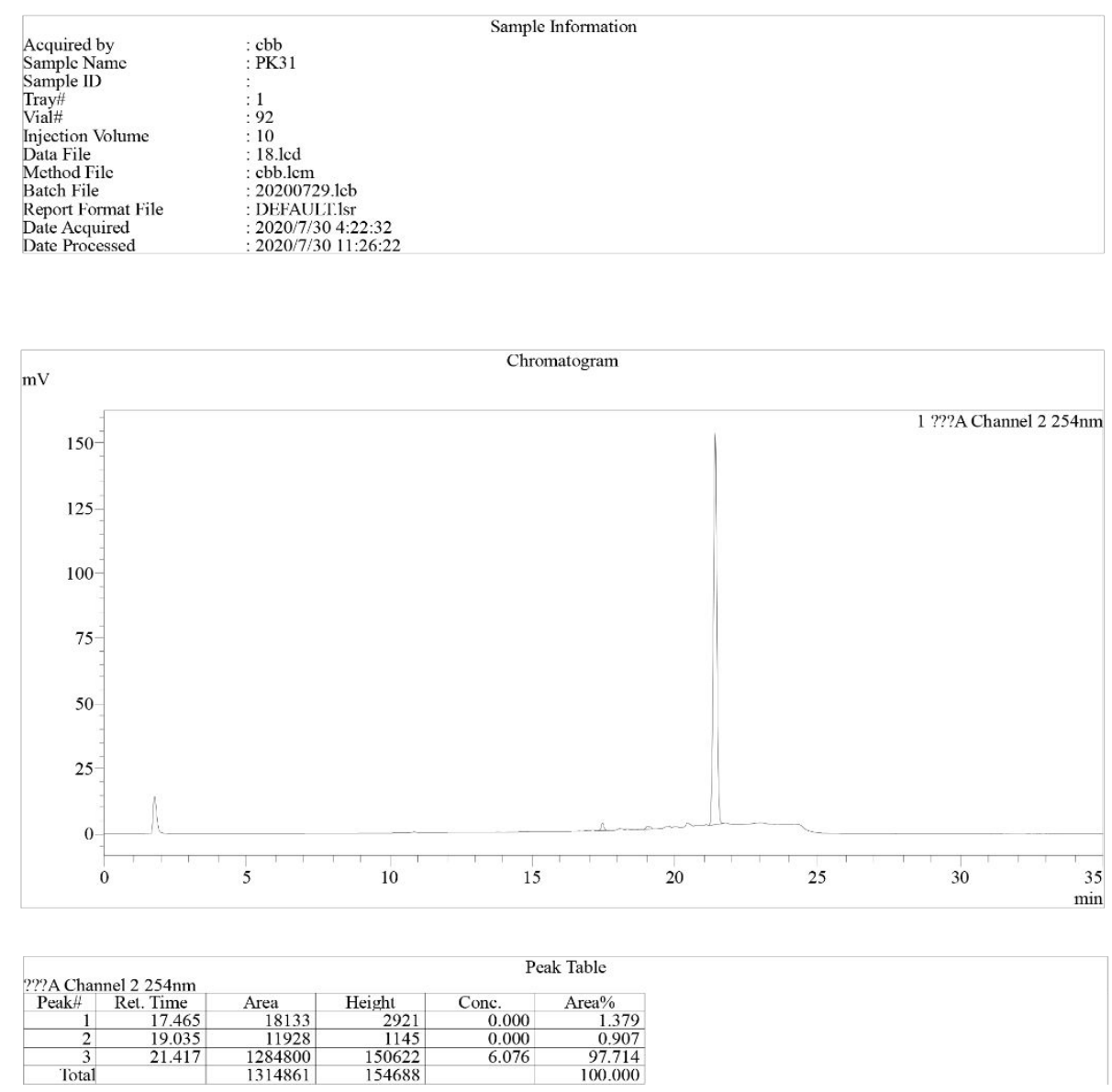

HPLC of compound P13.

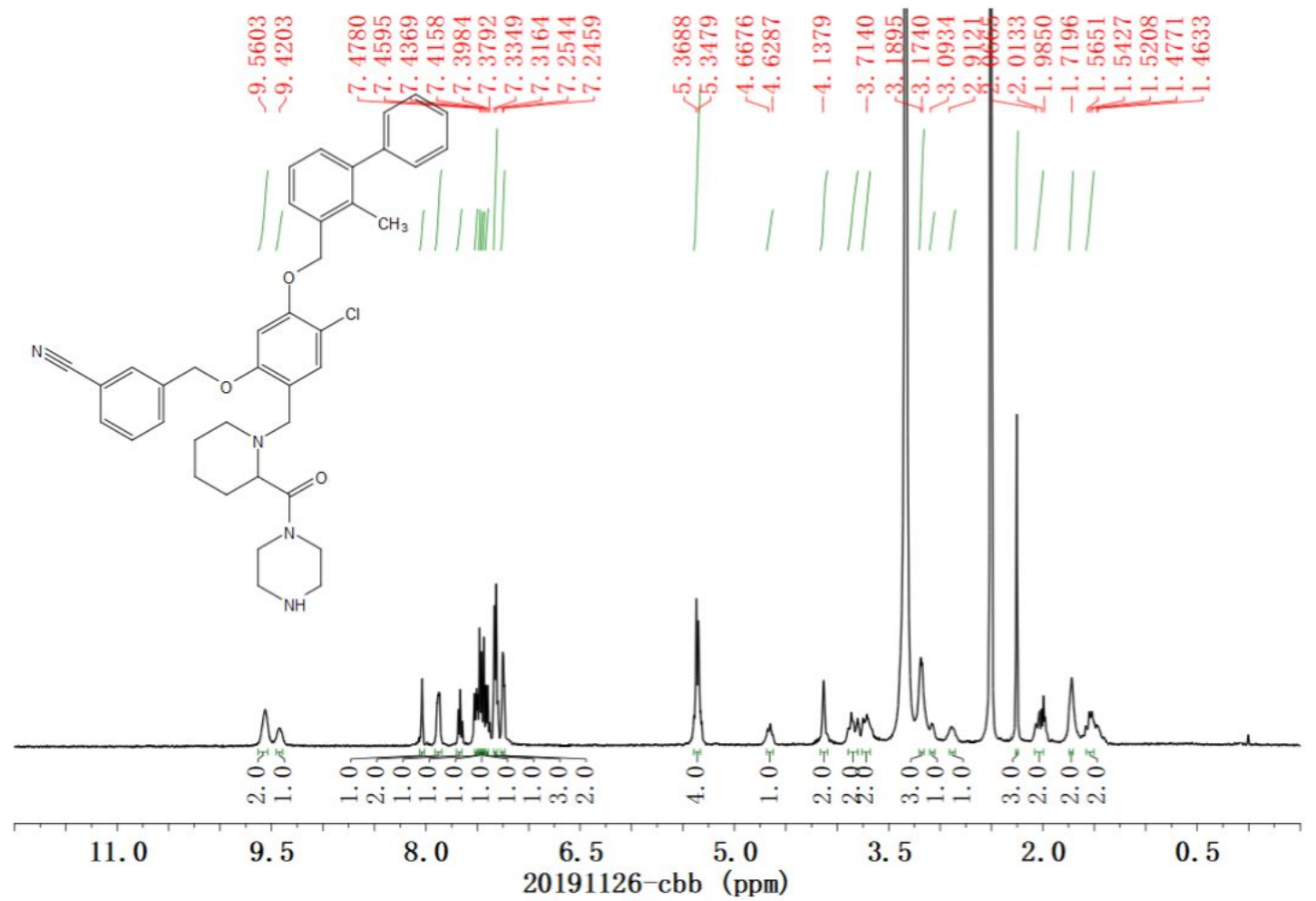

${ }^{1} \mathrm{H}$ NMR of compound P14. 


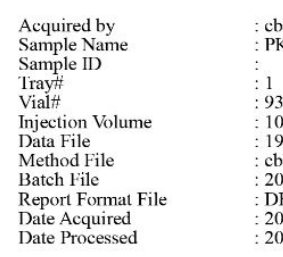

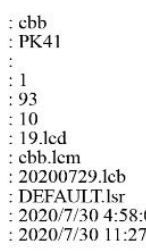

Sample Information

$\mathrm{m}$

Chromatogram

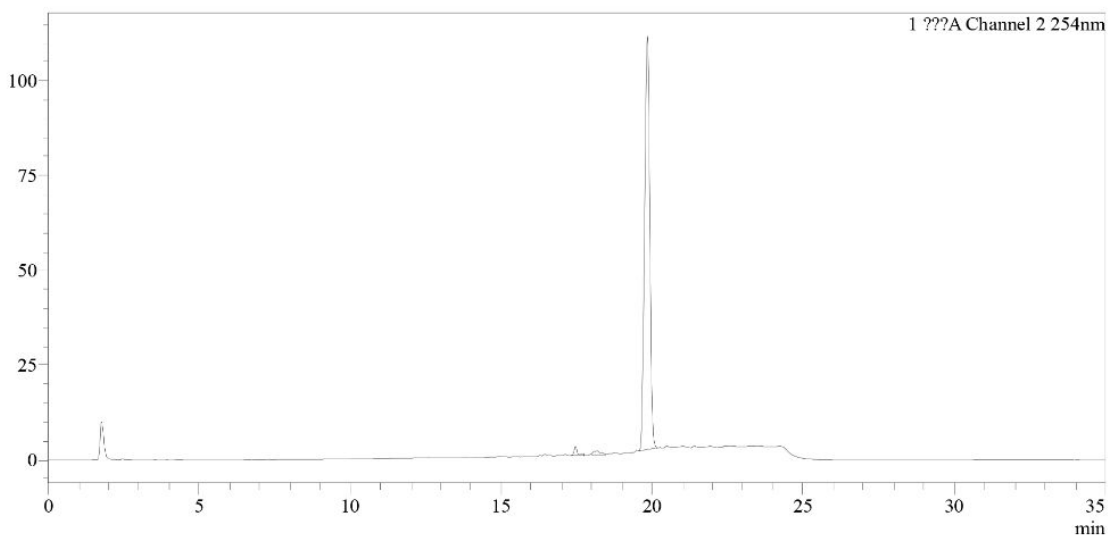

Peak Table

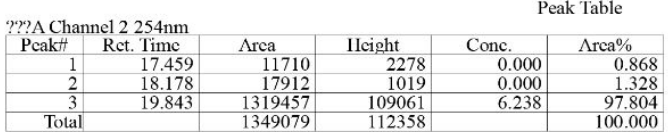

HPLC of compound P14.

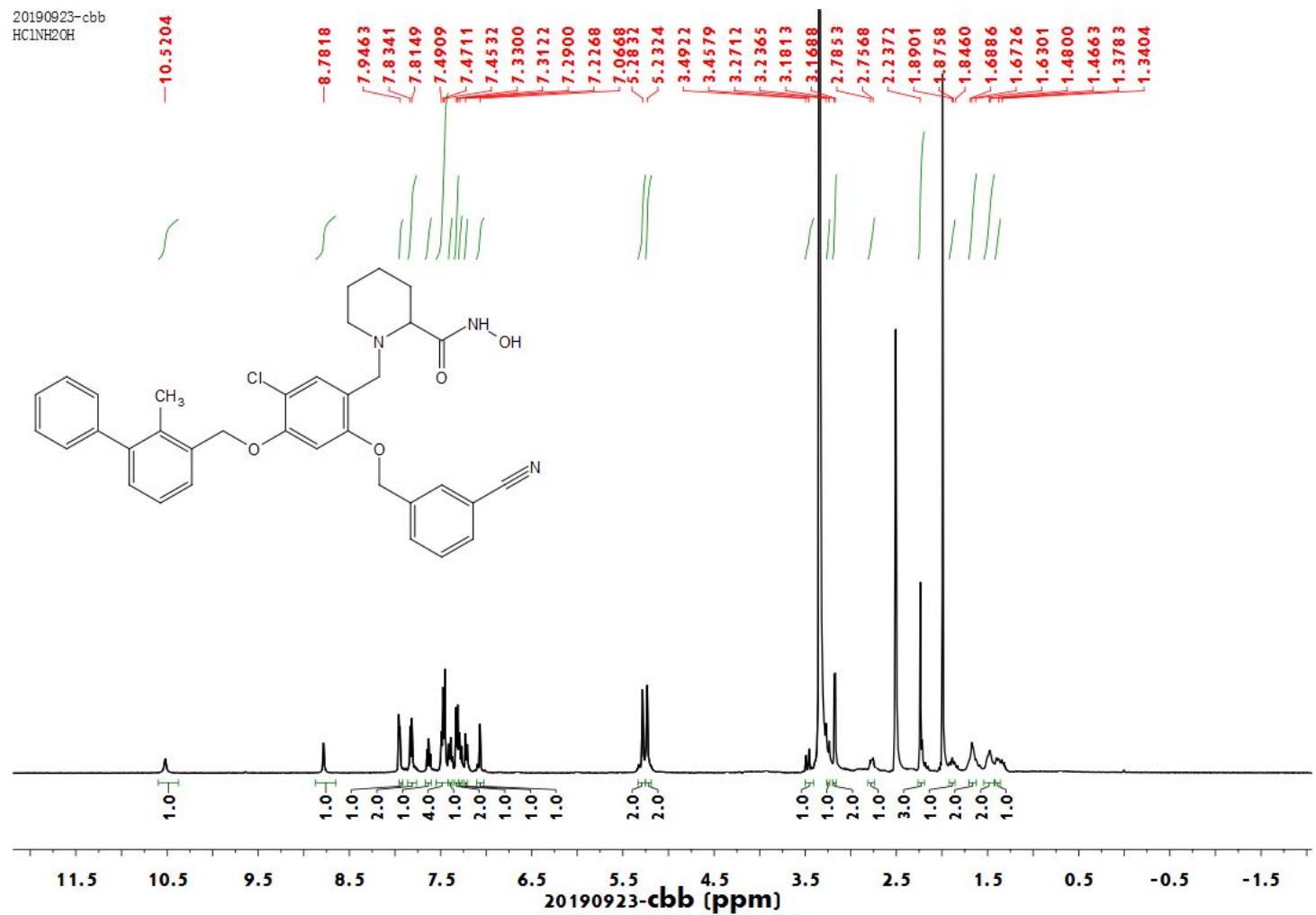

${ }^{1} \mathrm{H}$ NMR of compound P15. 


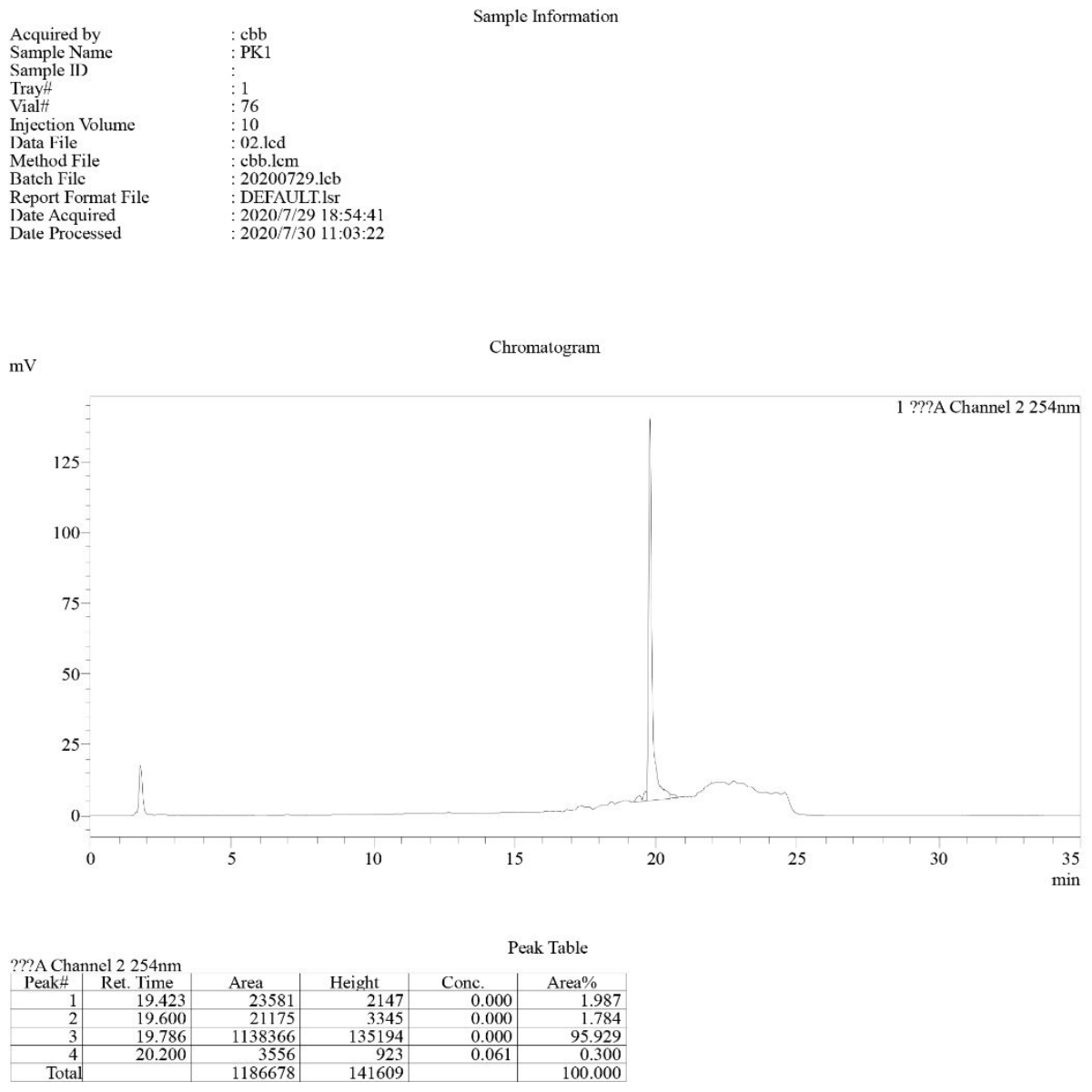

HPLC of compound P15.

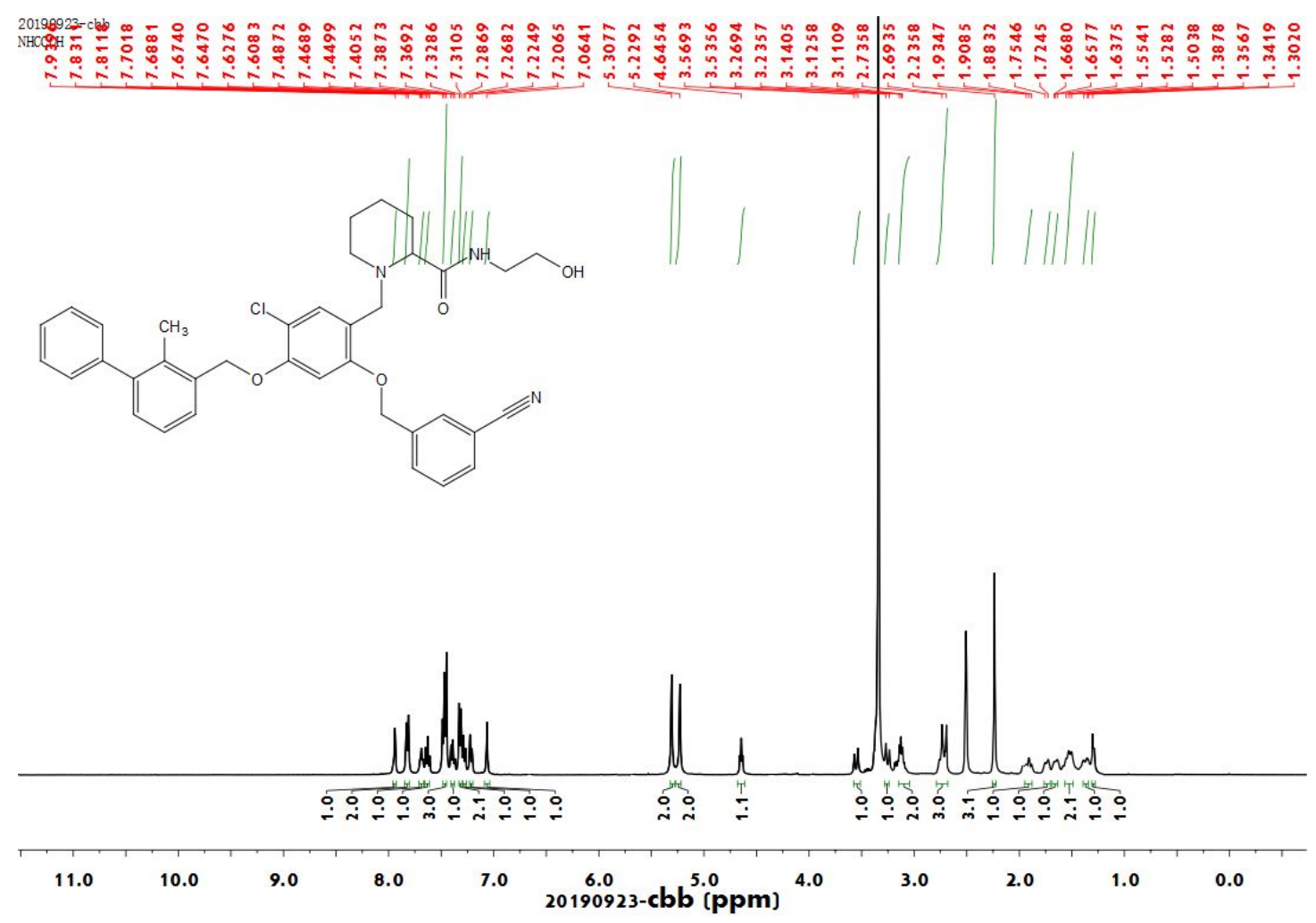

${ }^{1} \mathrm{H}$ NMR of compound P16. 


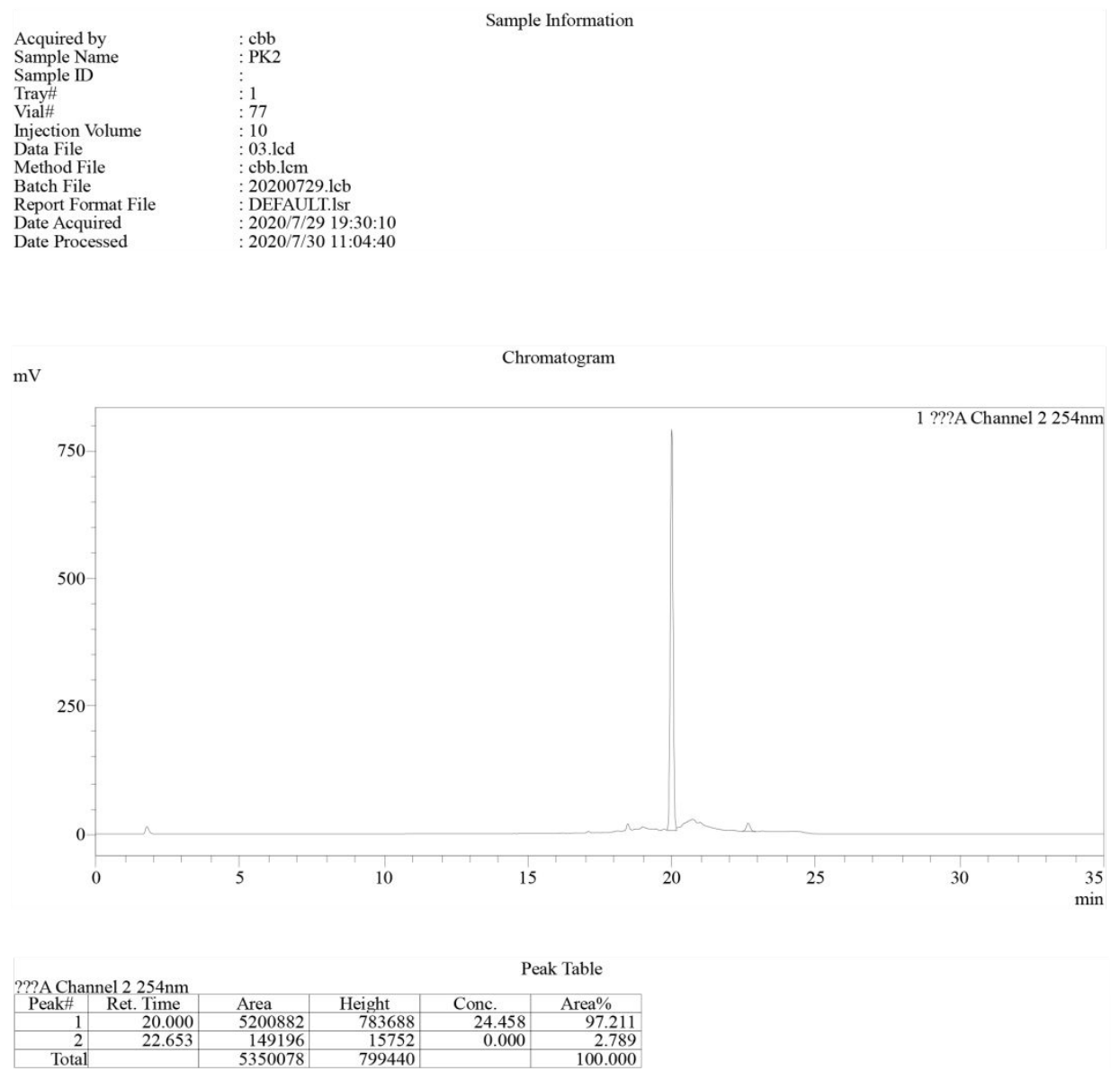

HPLC of compound P16.

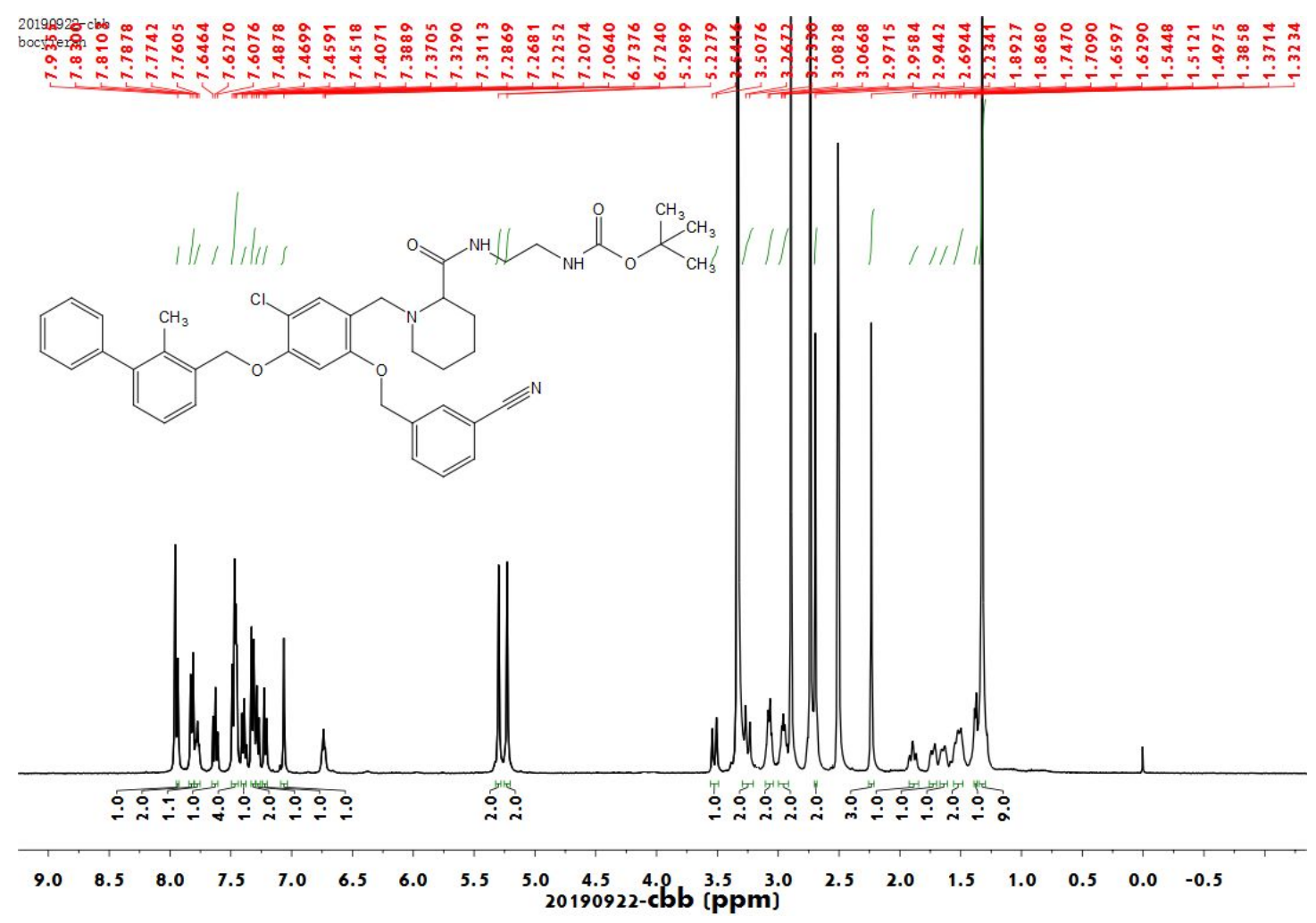

${ }^{1}$ H NMR of compound P17. 

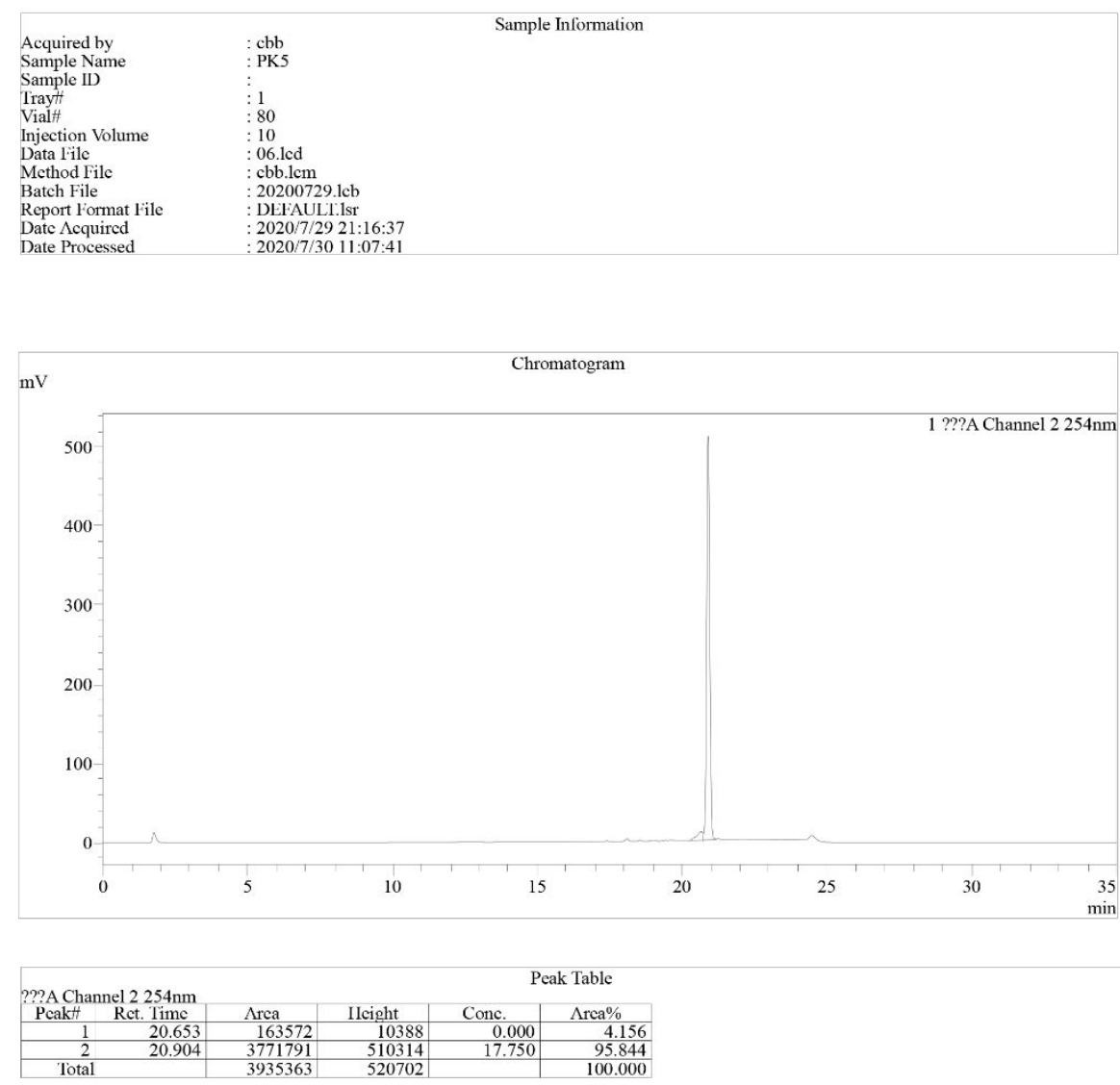

HPLC of compound P17.

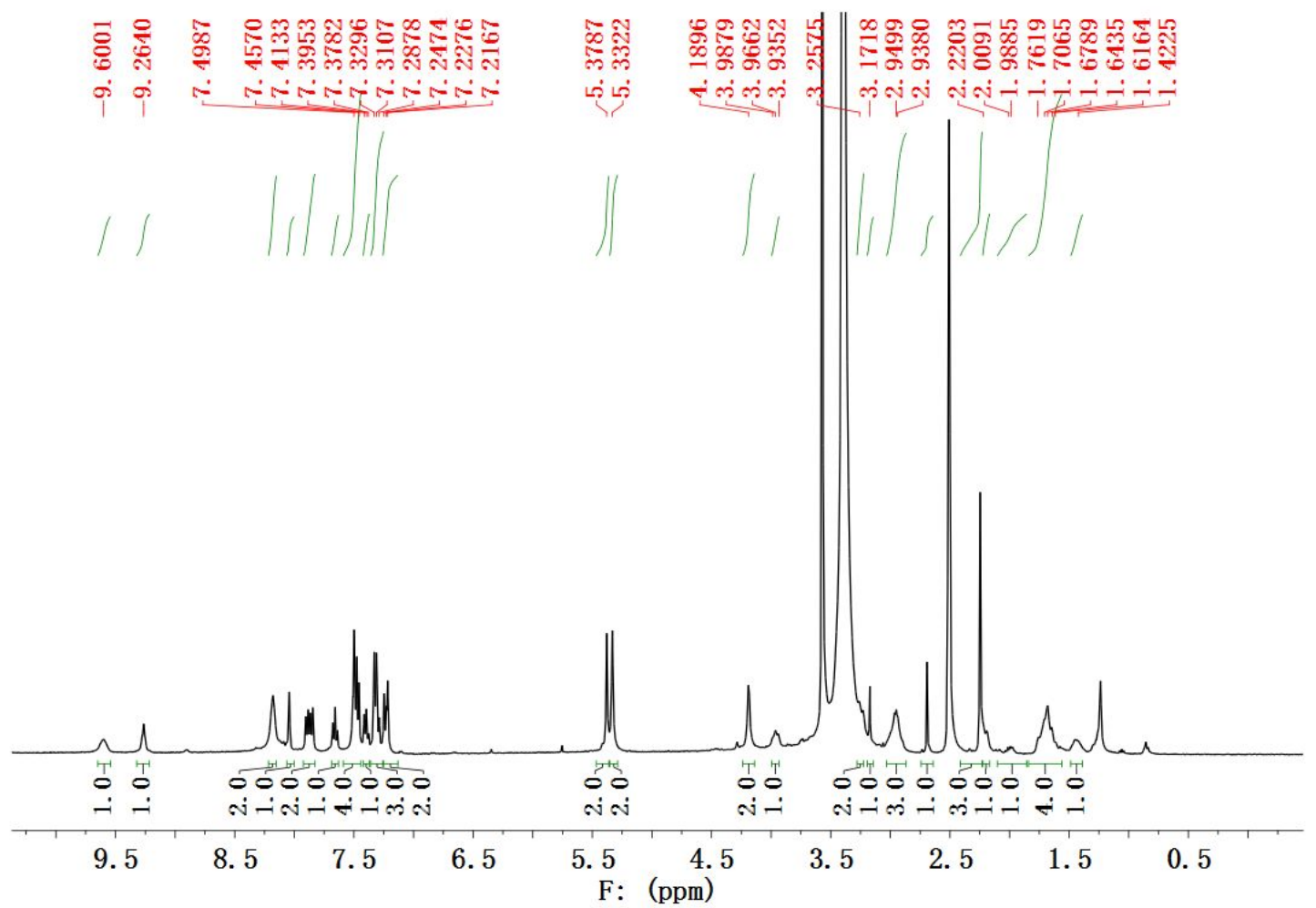

${ }^{1} \mathrm{H}$ NMR of compound P18. 


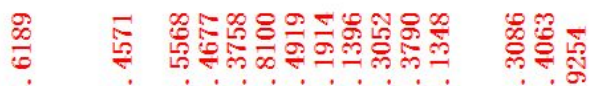

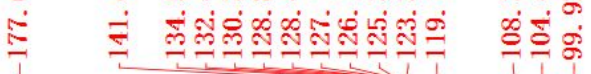
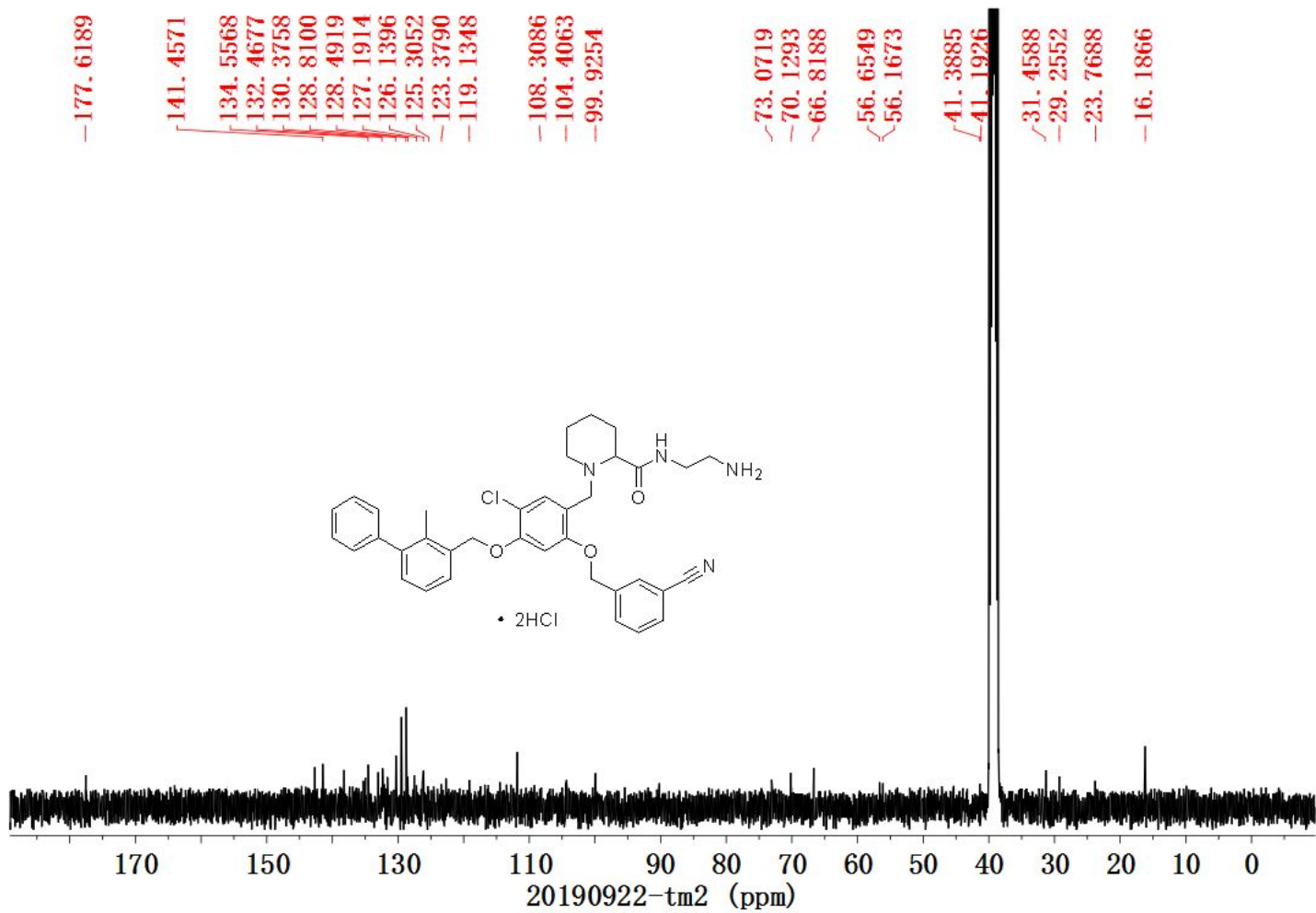

${ }^{13} \mathrm{C}$ NMR of compound P18.

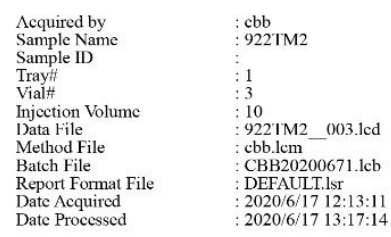

Sample Information

$\mathrm{mV}$

Chromatogram
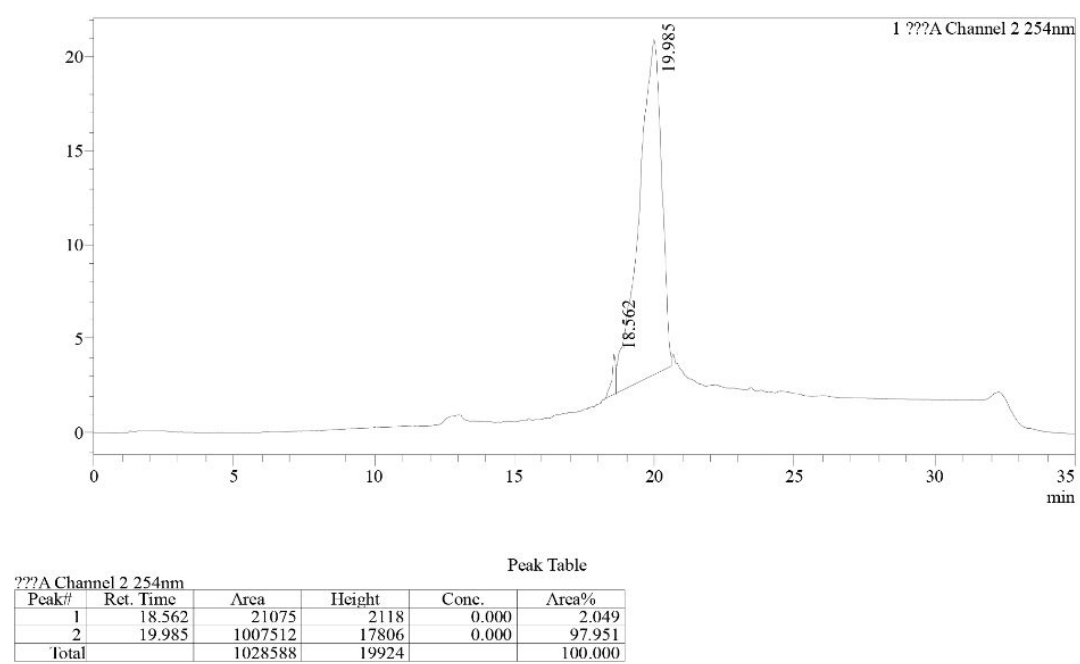

HPLC of compound P18. 


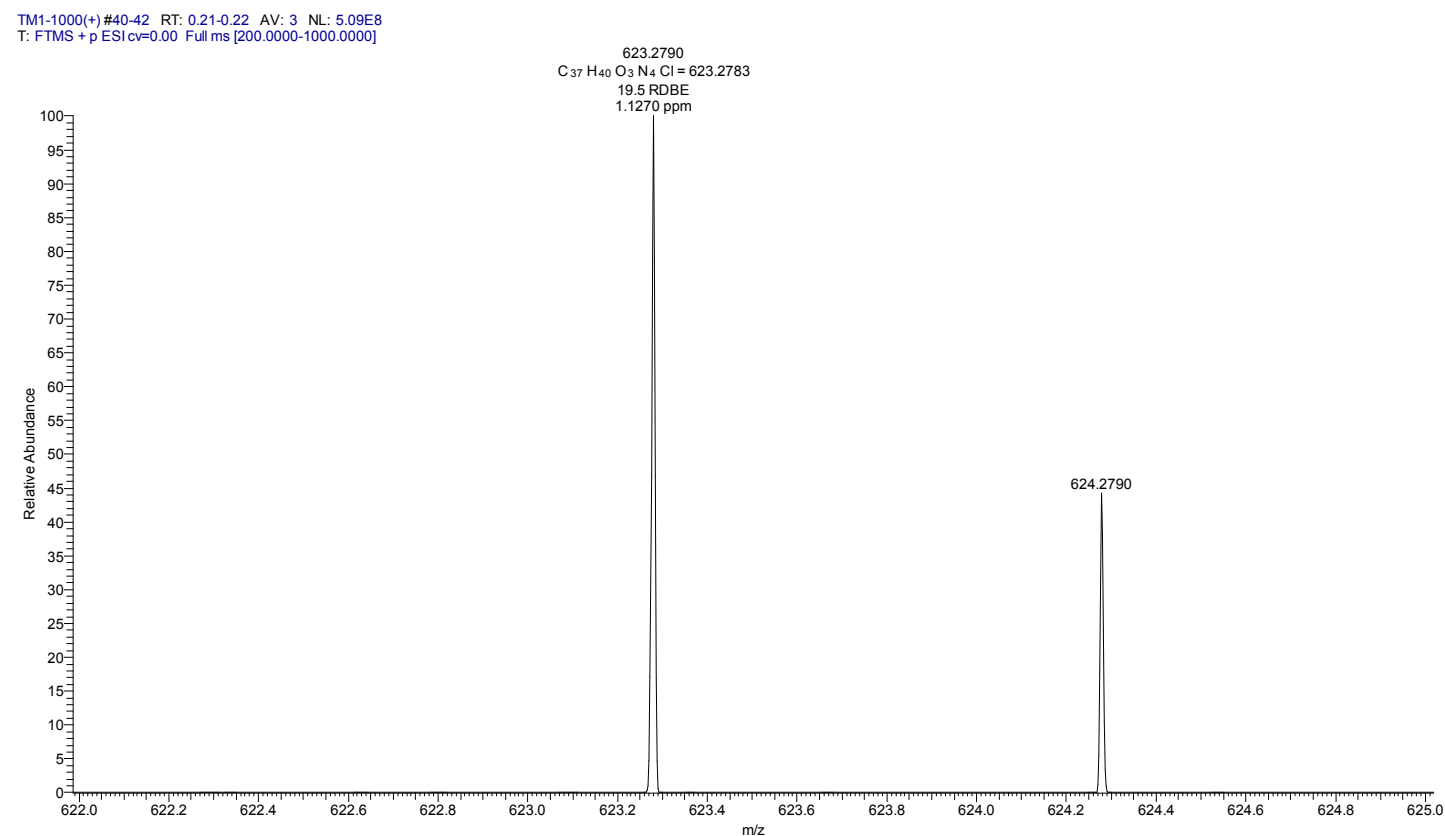

HRMS of compound P18.
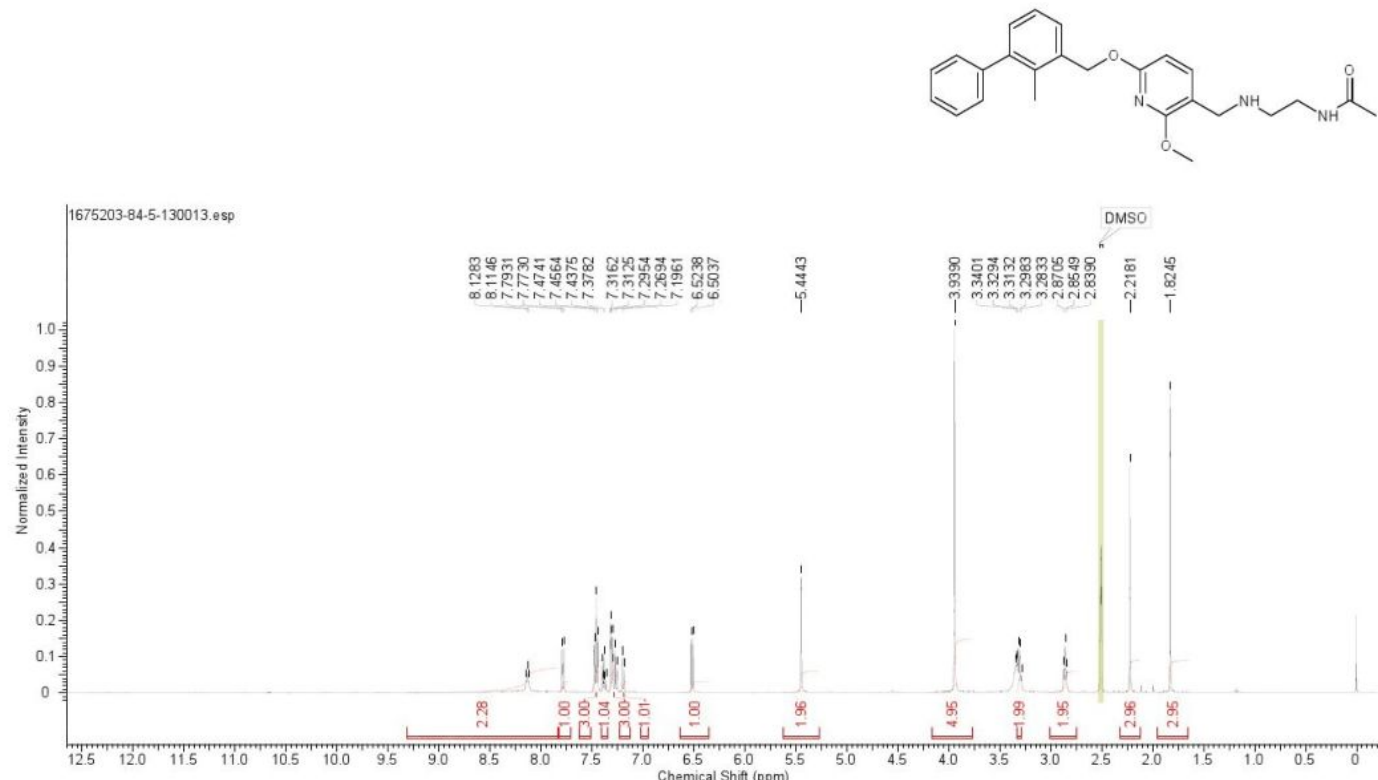

${ }^{1} \mathrm{H}$ NMR of compound BMS-202. 


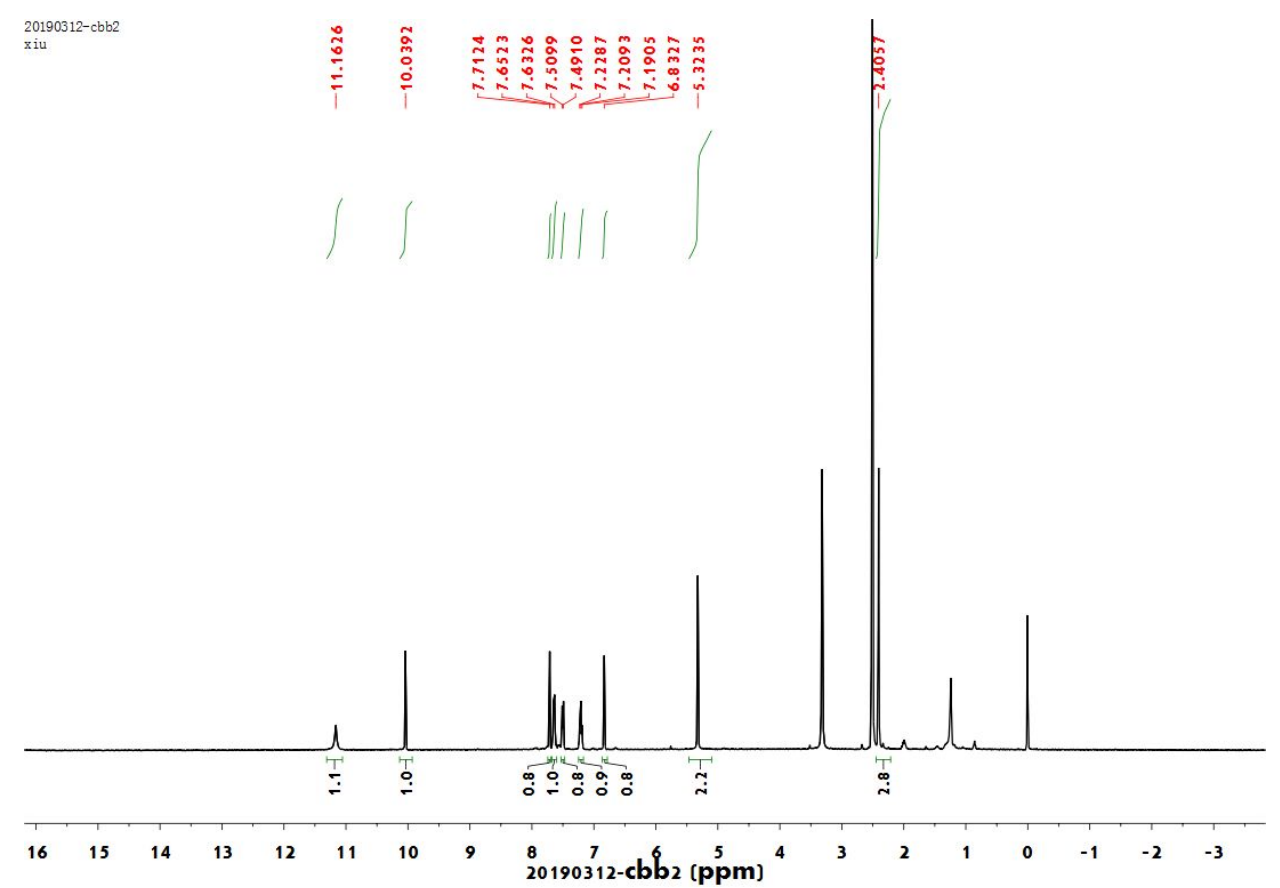

${ }^{1} \mathrm{H}$ NMR of compound 2.

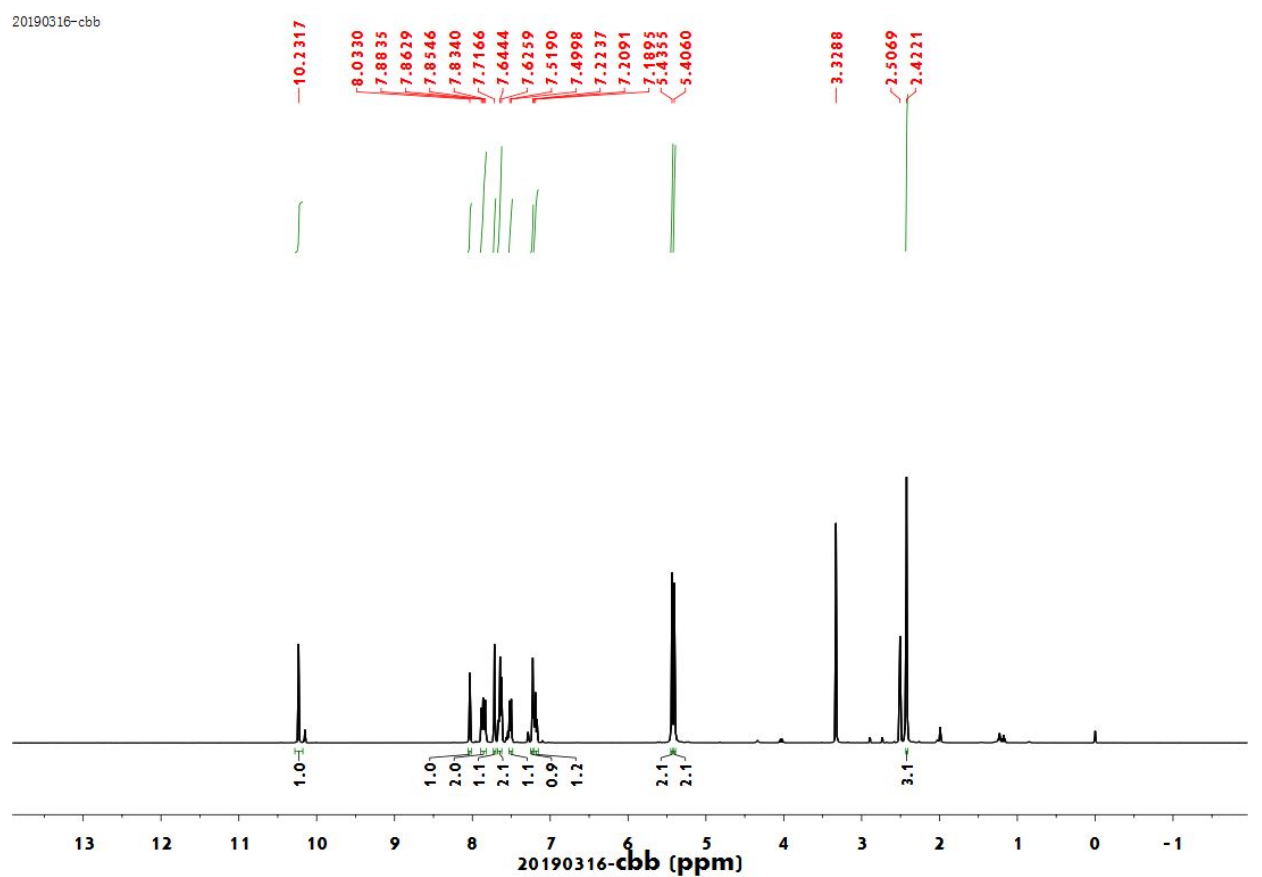

${ }^{1} \mathrm{H}$ NMR of compound 3 . 


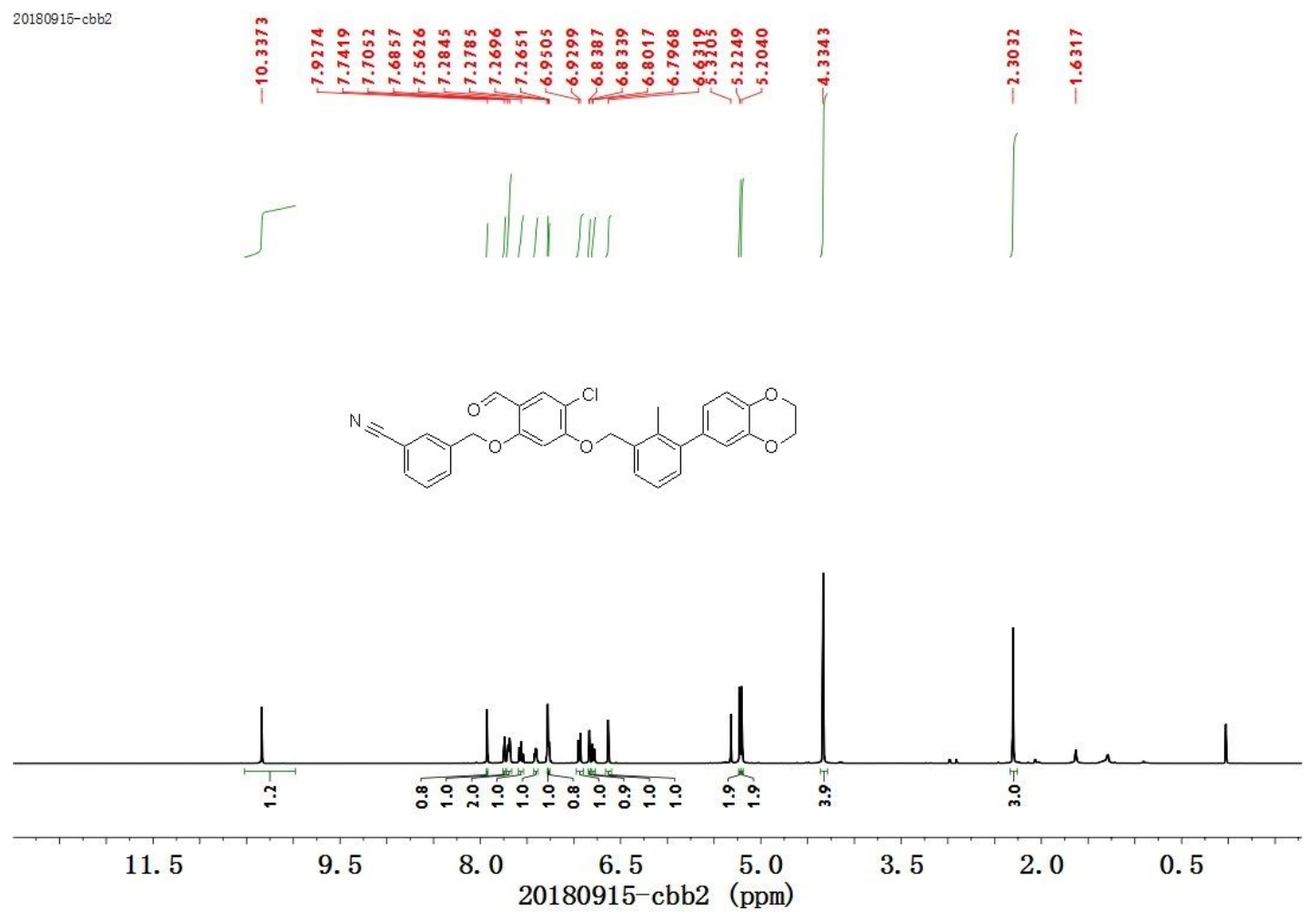

${ }^{1} \mathrm{H}$ NMR of compound $\mathbf{4 a}$.

20180915-cbb2
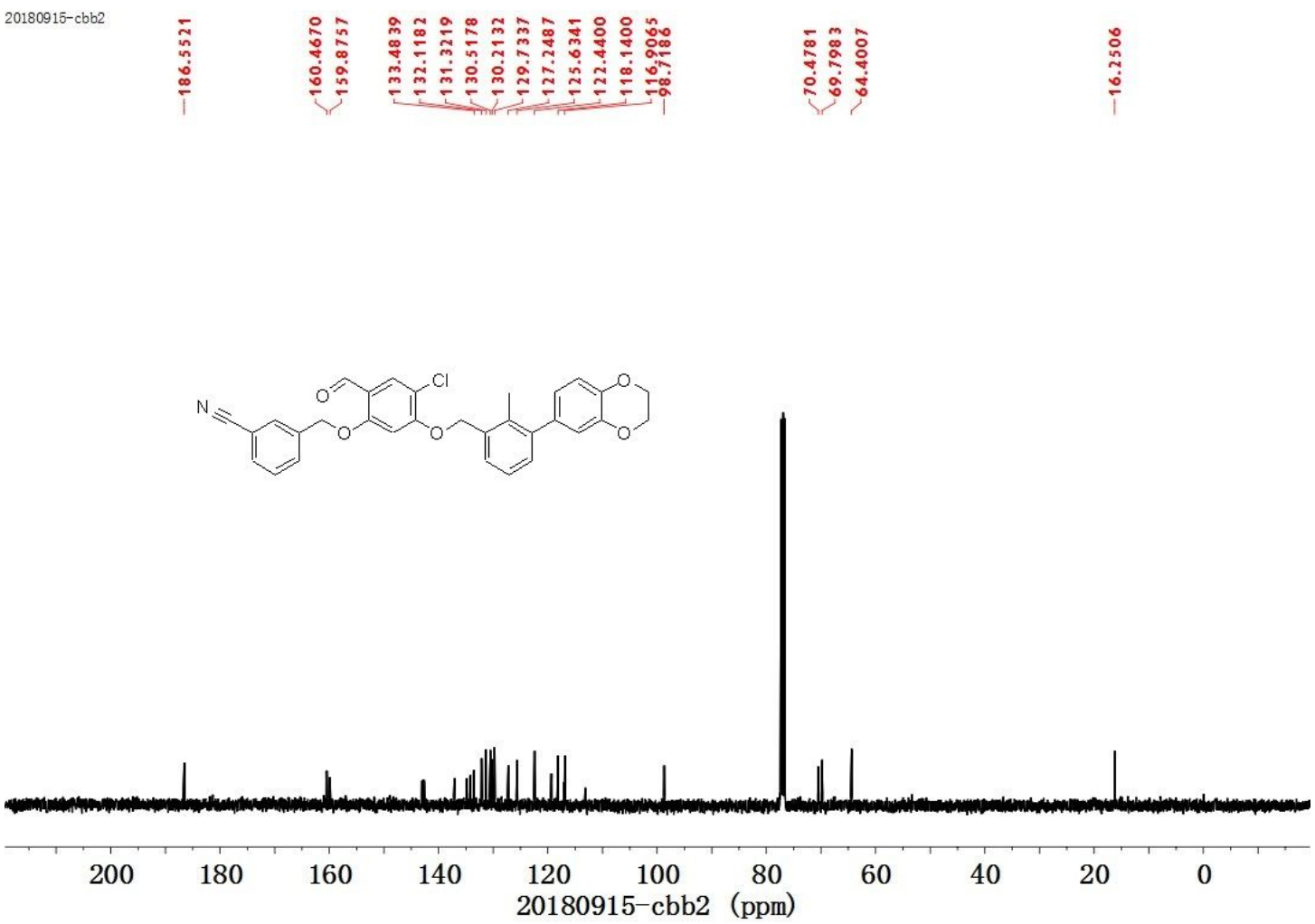

${ }^{13} \mathrm{C}$ NMR of compound $4 \mathbf{a}$. 


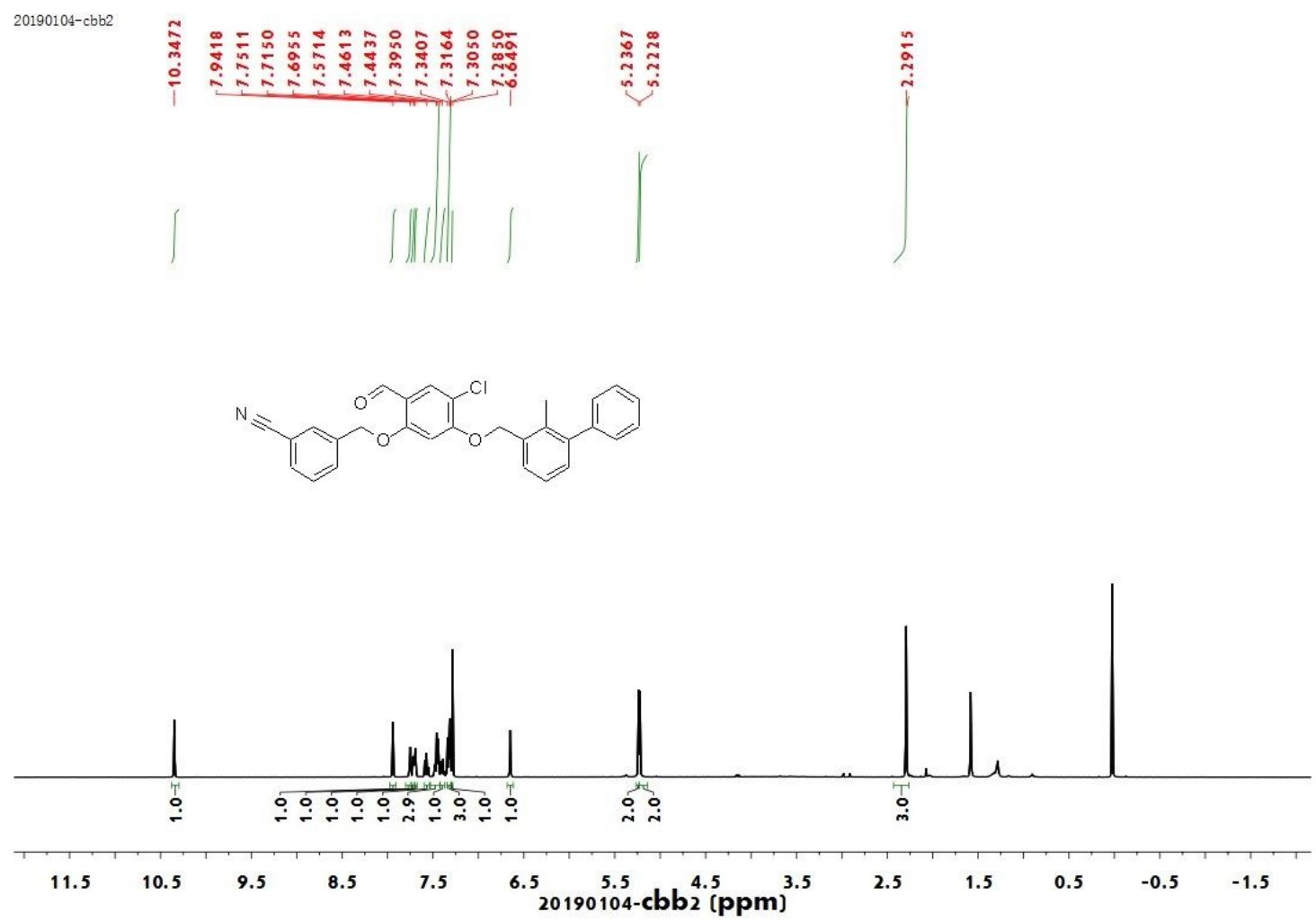

${ }^{1} \mathrm{H}$ NMR of compound $\mathbf{4 b .}$ 